\title{
Activation of chloride channels with the anti-parasitic agent ivermectin induces membrane hyperpolarization and cell death in leukemia cells
}

\section{By}

Sumaiya Sharmeen

A thesis submitted in conformity with the requirements for the degree of Master of Science Graduate Department of Medical Biophysics University of Toronto

C Copyright by Sumaiya Sharmeen (2010) 


\title{
Activation of chloride channels with the anti-parasitic agent ivermectin induces membrane hyperpolarization and cell death in leukemia cells
}

\author{
Degree of Master of Science, 2010 \\ Sumaiya Sharmeen \\ Department of Medical Biophysics \\ University of Toronto
}

\begin{abstract}
FDA-approved drugs with previously unrecognized anti-cancer activity could be rapidly repurposed for this new indication. We compiled a library of such off-patent drugs to screen four leukemia cell lines and identified the anti-parasitic agent ivermectin that induced cell death at low micromolar concentrations. In cell death and clonogenic growth assays, low micromolar concentration of ivermectin significantly reduced viability of leukemia cell lines and patient samples compared to normal peripheral blood stem cells. In xenograft mouse models of leukemia, ivermectin decreased tumor volume and weight by up to $72 \%$ when compared to control without observable toxicity at pharmacologically achievable dosage. In this study, we further demonstrate that ivermectin activates chloride channels in leukemia cells leading to membrane hyperpolarization and increased reactive oxygen species generation. In addition, it demonstrated synergistic interaction when used in combination with Daunorubicin and Cytarabine. Therefore, this study highlights a potential new therapeutic strategy in repurposing ivermectin for the treatment of AML.
\end{abstract}




\section{ACKNOWLEDGEMENTS}

I am deeply indebted to my supervisor, Dr. Aaron Schimmer, from University of Toronto whose help, stimulating suggestions and encouragement helped me complete this research project successfully and write this thesis. I would like to thank my Committee members, Dr. Mark Minden and Dr. Dwayne Barber, for giving me insightful advice and comments that enabled me to progress through this project.

I would also like to thank the wonderful team at Dr. Schimmer's lab for their abundant support and cooperation. I would like to acknowledge here especially those who have contributed to this project: Marko Skrtic, Mahadeo A. Sukhai, Rose Hurren, Marcela Gronda, Xiaoming Wang. I would like to thank our collaborators, Sonali Fonesca, Shana Kelly, Alessandro Datti and Jeffery Wrana for providing us with resources, ideas and help with experiments.

Lastly, I would like to thank my family for giving me a nurturing environment and teaching me values that have helped me succeed thus far. While my father has been my strength, my mother has been my inspiration for all that I have achieved. I dedicate my work to them. 


\section{TABLE OF CONTENTS}

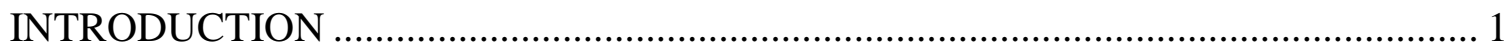

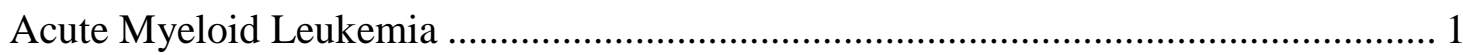

Repurposing an off-patent drug, Ivermectin, for the treatment of AML ........................ 4

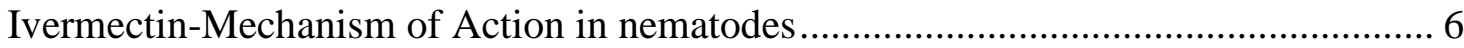

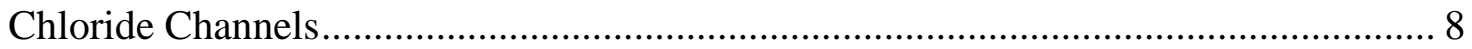

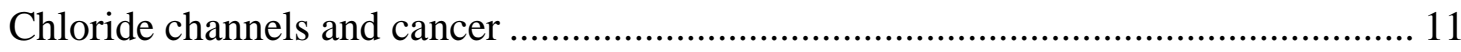

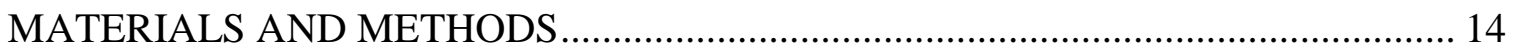

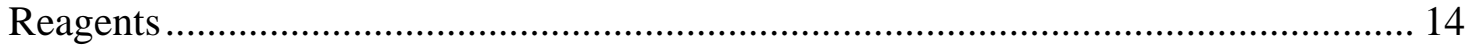

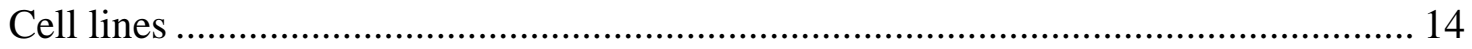

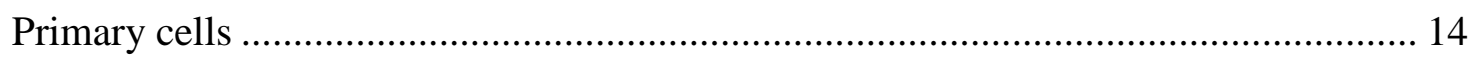

Chemical screen for cytotoxic compounds ……….............................................. 15

Cell viability assays ........................................................................................ 15

Assessment of Ivermectin's anticancer activity in mouse models of leukemia............ 16

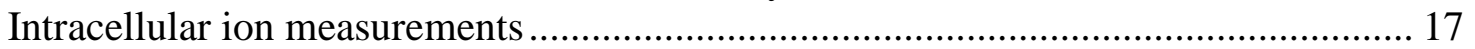

Determination of plasma membrane potential ............................................................ 17

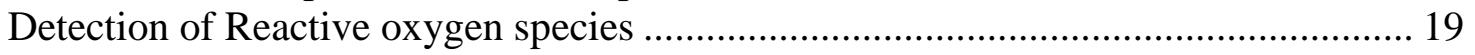

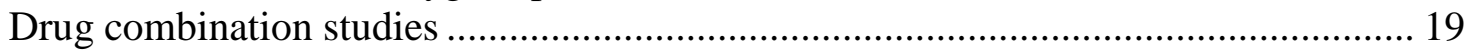

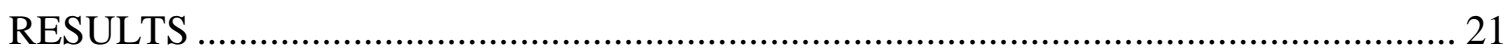

A chemical screen identifies ivermectin with potential anti-cancer activity ................ 21

Ivermectin is cytotoxic to malignant cell lines and primary patient samples ............... 22

Ivermectin delays tumor growth in mouse models of leukemia .................................. 24

Ivermectin induces intracellular chloride flux and hyperpolarization of the plasma

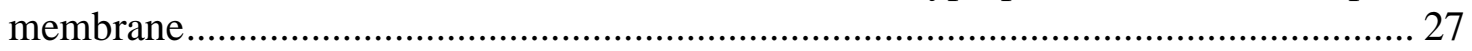

Ivermectin increases intracellular calcium but is not functionally important in leukemia

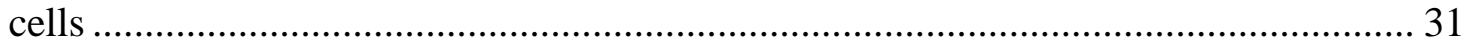

Ivermectin increases intracellular reactive oxygen species ...................................... 34

Ivermectin synergizes with cytarabine and daunorubicin.......................................... 36

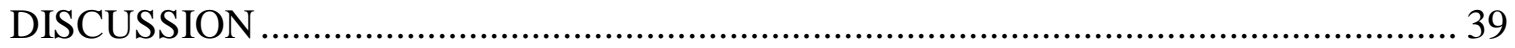

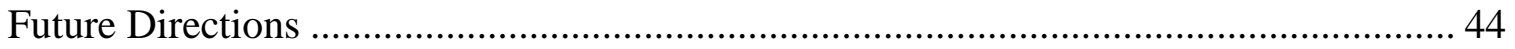

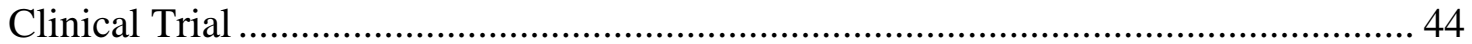

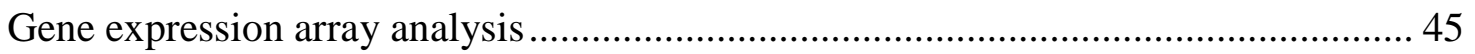

Lentiviral shRNA screen to identify genes in the ivermectin response pathway ......... 47

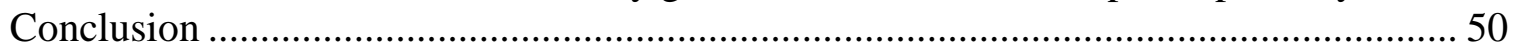

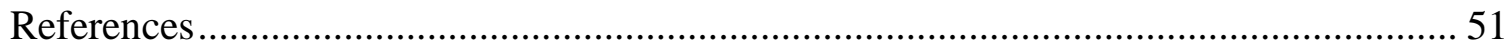




\section{SUMMARY OF FIGURES}

Figure 1: Screen of off-patent drugs identifies antiparasitic agent ivermectin that reduces viability of malignant cells in vitro.

Figure 2: Ivermectin delays tumor growth and reduces tumor weight in leukemia mouse xenografts.

Figure 3: Ivermectin induced a chloride influx and hyperpolarization of the plasma membrane 31

Figure 4: Ivermectin induces a calcium influx in OCI AML2 cells.. 34

Figure 5: Ivermectin induces generation of reactive oxygen species. 36

Figure 6: Ivermectin synergizes with cytarabine and daunorubicin to induce cell death in leukemia cells. 


\section{INTRODUCTION}

\section{Acute Myeloid Leukemia}

Acute Myeloid Leukemia (AML) is a heterogenous hematopoietic disorder that is characterized by a block in differentiation of myeloid precursor cells resulting in growth of clonal population of malignant or blast cells. The neoplastic transformation of the hematopoietic cells often leads to a loss of normal hematopoietic function due to lack of mature granulocytes and monocytes as well as decreased red blood cell and platelet production, causing death among leukemia patients within weeks to months of its clinical presentation if left untreated.

Heredity, chemical exposure, radiation and drugs have been implicated to play a role in the development of AML. Certain syndromes with somatic cell chromosome aneuploidy such as trisomy 21 as observed in Down syndrome, inherited diseases with defective DNA repair and mutations in the granulocyte colony-stimulating factor (GCSF) are a few examples of hereditary conditions that have been associated with AML. ${ }^{1,2}$ Myeloproliferative syndromes, characterized by the proliferation of 1 or a few cell lineages such as granulocytic, erythroid, megakaryocytic or mastocytic, can also evolve to AML. ${ }^{3}$ Alkylating agents, topoisomerase II inhibitor and other anticancer drugs can result in bone marrow failure that evolve into AML and thus they have been linked to the pathogenesis of AML., ${ }^{4,5}$

Genetic abnormalities in leukemic cells and the age of patients are closely linked with the prognosis of AML patients. There are three broad prognostic categories of AML 
based on cytogenetic findings: favorable, intermediate and adverse. Although the specific abnormalities that fall under each of these stratifications is heavily debated amongst the various research groups, a general consensus exists. According to large cytogenetic studies of AML patients, patients with $\mathrm{t}(15 ; 17)(\mathrm{q} 22 ; \mathrm{q} 12-21)$ have an excellent and those with $\mathrm{t}(8 ; 21)(\mathrm{q} 22 ; \mathrm{q} 22)$ or $\operatorname{inv}(16)(\mathrm{p} 13 \mathrm{q} 22) / \mathrm{t}(16 ; 16)(\mathrm{p} 13 ; \mathrm{q} 22)$ a relatively favorable prognosis. ${ }^{6,7}$ Patients with inv(3)(q21q26)/ t(3;3)(q21;q26), -7 and a complex karyotype, defined in some studies as containing at least 3 and in others at least 5 chromosome aberrations, on the other hand have a poor clinical outcome. ${ }^{8}$ Furthermore, AML patients with $\operatorname{del}(7 \mathrm{q})$ in the absence of $-5 / \operatorname{del}(5 \mathrm{q}), \mathrm{t}(9 ; 11)(\mathrm{q} 22 ; 23),-\mathrm{Y},+8,+11,+21,3 \mathrm{q}$ abnormalities or a normal karyotype are classified in the intermediate risk category. ${ }^{9}$ The aberrant cytogenetics result in fusion proteins including several transcription factors and protein kinases that play essential roles in complex signaling pathways, which ultimately leads to leukemia through inhibition of normal myeloid differentiation as well as providing neoplastic cells with a survival advantage., ${ }^{1,210,11}$

Adverse cytogenetic abnormalities accumulate and increase with the age of patients and thus prognosis with standard treatment worsens with increasing age. A study reports that the percentage of favorable cytogenetics dropped from $17 \%$ in patients aged younger than 56 years to $4 \%$ in those aged older than 75 years. On the contrary, the percentage of patients with unfavorable cytogenetics increased from $35 \%$ in those younger than 56 years to $51 \%$ in patients older than 75 years. ${ }^{12}$ Patients with normal karyotype make up the largest subtype of AML (40-50\%) but these patients do not respond to treatments equally. The large variability in acquired gene mutations and gene expression in this population make them respond to therapy differentially. Patients with 
mutations in the CCAAT/enhancer-binding protein- $\alpha$ gene or the nucleophosmin 1 gene respond to treatments more favorably than patients with internal tandem duplications of the FMS-like tyrosine kinase 3 (FLT3), partial tandem duplication of the myeloid/lymphoid or mixed lineage leukemia gene, overexpression of the brain and acute leukemia gene and overexpression of the ETS-related gene. ${ }^{10,11,13-15}$

For the past 3 decades, the standard initial therapy of AML has been induction chemotherapy with 7 days of continuous intravenous infusion of cytarabine 100-200 $\mathrm{mg} / \mathrm{m}^{2}$ and 3 days of daunorubicin 45 to $90 \mathrm{mg} / \mathrm{m}^{2}$ ("7 and 3 "). ${ }^{16}$ Although there have been other studies that investigated alternatives to this standard treatment by increasing dosage of cytarabine or substituting other antracyclines instead of daunorubicin, none have consistently shown the significant improvement over "7 and 3". ${ }^{17,18}$ Patients with de novo disease may benefit and show complete remission in 50-90\% of patients with modern induction chemotherapy. However, the success of achieving high remission rate with initial chemotherapy regiment is hindered due to the relapse seen within 3 years of diagnosis in majority of the patients. As a result, between 10 to $25 \%$ of patients will have primary refractory disease indicate by non-response to prior therapy, early first relapse or multiple relapses. ${ }^{19,20}$

Relapsed AML is a highly aggressive and resistant disease, particularly when associated with complete response duration of less than 12 months and rates of second remission after such a rapid relapse are lower (25-30\% vs 60\%) and remissions are briefer. $^{21}$ Postremission therapy traditionally involved two standard acceptable modalities, i.e. more chemotherapy (high dose cytarabine in patients younger than 60 years old) and allogenic bone marrow transplantation (BMT). Patients who fall in the 
unfavorable risk group, as well as older patients, do not benefit from the intensive consolidation chemotherapy regimen as seen by their low complete remission rate of approximately $20 \%$ after reinduction and disease relapse shortly after treatment. Since AML is mainly a disease of the elderly who are often deemed too frail because of their unfavorable cytogenetics and co-morbities, this population may stand to benefit the most from novel agents that can be less toxic than current agents. The inadequate cure rates for adults with AML stresses the need for new research approach to find therapeutic agents that are less toxic and more effective than current agents.

\section{Novel application of an off-patent drug, Ivermectin, for the treatment of $A M L$}

Antimicrobials with previously unrecognized anti-cancer activity can be rapidly repurposed for this new indication given their extensive prior pharmacology and toxicology testing. For example, the broad spectrum antiviral ribavirin was found to suppress oncogenic transformation by disrupting the function and subcellular localization of the eukaryotic translation initiation factor eIF4E $\mathrm{E}^{22,23}$. As such ribavirin was recently evaluated in a phase I dose escalation study in patients with relapsed or refractory M4/M5 acute myeloid leukemia (AML). In this study of 13 patients treated with ribivarin, there was 1 complete remission, and 2 partial remissions. Thus, ribivarin may be efficacious for the treatment of $\mathrm{AML}{ }^{24}$ Likewise, the anti-fungal ketoconazole inhibits the production of androgens from the testes and adrenals in rats. Given this finding, ketoconazole was rapidly advanced into clinical trials for patients with prostate cancer where it displayed clinical efficacy in early studies. ${ }^{25,26}$ 
Recently we demonstrated that the anti-parasitic clioquinol inhibits the proteosome and induces cell death in leukemia and myeloma cells through copper dependent and independent mechanisms ${ }^{27}$. Thus, our preclinical data suggests that this antiparasitic could be repurposed for the treatment of haematological malignancies. Therefore, we initiated a phase 1 study to evaluate the dose-limiting toxicity, maximum tolerated dose, and recommended phase II dose of Clioquinol in patients with relapsed or refractory hematologic malignancies (ClinicalTrials.gov Identifier: NCT00963495.)

Here we used a chemical screen to identify known drugs with previously unrecognized activity against leukemia. From this screen, we identified the anti-parasitic agent ivermectin. Ivermectin is a derivative of avermecin B1 and licensed for the treatment of strongyloidiasis and onchocerciasis parasitic infections and other worm infestations (e.g., ascariasis, trichuriasis and enterobiasis) but has not been previously tested as an anti-cancer agent. As part of the development of this agent as an antiparasitic agent, ivermectin was extensively evaluated for its pharmacology, safety and toxicity in humans and animals. For example, the $\mathrm{LD}_{50}$ of oral ivermectin in mice, rats and rabbits ranges from 10 to $50 \mathrm{mg} / \mathrm{kg}^{28}$. In humans, when used to treat onchocerciasis, $100-200$ $\mu \mathrm{g} / \mathrm{kg}$ of ivermectin is administered as a single dose $\mathrm{e}^{29}$. This brief and low-dose treatment is sufficient to achieve an anti-parasitic effect, but higher doses and treatment beyond one day have been safely administered for other conditions. For example, in patients with spinal injury and resultant muscle spasticity, up to $1.6 \mathrm{mg} / \mathrm{kg}$ of ivermectin was administered subcutaneously at twice weekly for up to 12 weeks. In this study, no significant adverse effects were reported. ${ }^{30}$ Likewise, to evaluate the safety of oral ivermectin, healthy volunteers received $30-120 \mathrm{mg}$ on days 1,4 and 7 and then a further 
dose in week $3 .^{31}$ Even at a dose of $120(\sim 2 \mathrm{mg} / \mathrm{kg})$ no serious adverse effects were noted. Finally, reports of ivermectin overdoses also support the evaluation of high doses of ivermectin in humans, as in the majority of these cases, no serious adverse events were reported. $^{32}$

In our current study, we demonstrated that ivermectin displayed preclinical activity against hematological malignancies in vitro and delayed tumor growth in vivo at concentrations that appears pharmacologically achievable. Mechanistically, ivermectin induced chloride influx, membrane hyperpolarization and generated reactive oxygen species. Furthermore, ivermectin synergized with cyatarabine and daunorubicin. Thus, given its prior safety and toxicity testing, ivermectin could be rapidly repurposed as a novel agent for the treatment of leukemia.

\section{Ivermectin-Mechanism of Action in nematodes}

\section{Structure of Ivermectin}

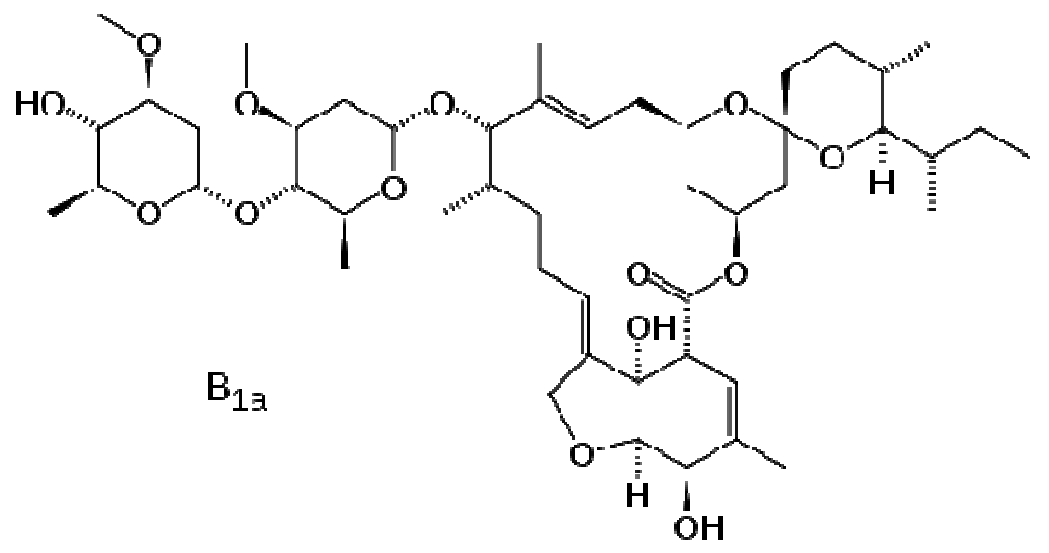

Ivermectin is a macrocyclic lactone, a natural product by the soil dwelling bacterium Streptomyces avermitilis. Although it has been used to treat infections caused by various strains of nematodes for decades, the mechanism by which it exerts its 
antihelmintic activity is not clear yet. However, it is proposed that ivermectin exerts its antihelmintic effects by interacting with ligand gated chloride channels, such as gammaaminobutyric acid (GABA), glutamate and glycine gated chloride channels.

Studies have shown that it induces a potent anthelmintic and insecticidal effect by immobilizing nematodes and blocking the signal transmission from the central command interneurons to the peripheral motor neurons. It is believed that the paralysis of nematodes results from the inhibition of both excitatory and inhibitory postsynaptic potentials at the neuromuscular junctions by ivermectin. By opening the GABA controlled chloride ion channels on the postsynaptic junction, ivermectin reduces the muscle membrane resistance and induces hyperpolarization by allowing chloride influx. $^{33-35}$ GABA is the neurotransmitter substance that mediates transmission of inhibitory signals from the interneurons to the motor neurons in the ventral nerve cord of parasites. Thus, this disruption of GABA signaling between nerve cells and muscle cells leads to neuromuscular blockade, paralysis and death of most parasites. ${ }^{33}$ Furthermore, it has been shown that ivermectin functions like other known GABAergic agonists in nematodes such as muscimol and piperazine. ${ }^{36}$ However, studies with crude membrane fraction prepared from the nematode, Caenorhabditis elegans (C. elegans) showed that several putative neurotransmitters including GABA, glutamate and dopamine did not alter binding of ivermectin, which suggests that ivermectin has an unique binding site that differs from these neurotransmitters. ${ }^{37}$

Furthermore, evidence of membrane currents that were recorded from Xenopus laevis oocytes injected with $C$. elegans poly(A)+ RNA showed that ivermectin directly activated the glutamate-sensitive current, which suggests that the chloride current 
induced by ivermectin may be mediated through the invertebrate specific glutamate gated chloride channel as well. ${ }^{38,39}$ The nematocidal drug ivermectin is believed to kill worms by opening a glutamate-gated chloride channel on pharyngeal muscle, causing complete pumping inhibition leading to starvation and death of the parasites. Pivotal work by Cully et. al. later demonstrated that the electrophysiological and structural properties of these chloride channels indicate that they are members of the ligand gated ion channel superfamily. ${ }^{40}$ Additional support for this hypothesis was observed when mutants lacking a functional glutamate gated chloride channel alpha2 subunit in the pharynx of c.elegans showed no response to ivermectin treatment. ${ }^{41}$ Sequences of alpha and beta subunits of glutamate gated chloride channels have been cloned from various parasitic nematodes of horses, cattle and other animals, suggesting that these parasites are sensitive to ivermectin treatment due to the presence of these channels. ${ }^{42-44}$ Literature review on the mechanism of ivermectin identified chloride channels as key modulators of ivermectin response and thus in malignant cells, ivermectin may target chloride channels or other ion channels to induce a cytotoxic effect. To further our understanding of chloride channels, a brief discussion on the types of mammalian chloride channels and their role in cancer progression is presented in the next section.

\section{Chloride Channels}

Anion channels provide a proteinaceous pore through which negatively charged ions like iodide, bromide, chloride and other anions can readily pass through along their electrochemical gradient. However, chloride is the most abundant and permeating anion in organisms and chloride channels can function on plasma and intracellular membranes. 
Chloride channels may be classified as to their localization (plasma membrane vs vesicular), single channel conductance or mechanism of regulation. However, this type of classification often leads to confusion because the same channel may reside in both plasma and vesicular membranes or may have overlapping mechanisms of actions. Thus, the classification of these chloride channels has been done based on their molecular structures. Mammalian chloride channels broadly fall into five classes based on their regulation: cystic fibrosis transmembrane conductance regulator (CFTR), calciumactivated chloride channels (CaCCs), voltage gated chloride channels (CICs), ligand gated chloride channels such as GABA and glycine activated and volume regulated chloride channels. Moreover, there are nine subtypes of $\mathrm{ClCs}(\mathrm{ClC} 1-\mathrm{ClC} 7, \mathrm{ClCKa}$ and $\mathrm{ClCKb}$ ) and ligand gated chloride channels are made of pentameric proteins formed by the assembly of different subunits. ${ }^{45}$ Each of these chloride channels are responsible for key cellular processes, which are described below.

Chloride channels on plasma membrane have been thought to play a role in regulating ionic homeostasis and cell volume, facilitating transepithelial transport and regulating membrane excitability. Chloride channels found intracellularly have been implicated in the regulation of organular volume, electroneutrality and organular acidification. ${ }^{45}$ Cytosolic chloride has been shown to be involved in the acidication of secretory and recyling endosomes of the trans-Golgi network. ${ }^{46}$ More specifically, CFTR, a cyclic AMP activated chloride channel found in the apical plasma membrane, is responsible for chloride secretion by epithelial cells in the airways, intestine, pancreas, testis and other fluid transporting tissues and chloride absorption in sweat glands. ${ }^{47}$ Mutation of this gene leads to the loss of its function by forming chloride impermeable 
channels that reduce secretion of chloride, bicarbonate and fluid by airway submucosal glands. As a result, the mutations promote bacterial colonization in the viscous, acidic airway surface liquid leading to lung infections as seen in patients with cystic fibrosis. ${ }^{48}$ Cytoplasmic calcium elevation activates $\mathrm{CaCCs}$ directly or through calcium/calmodulin kinase II (CaMKII)-mediated phosphorylation and the consequences of the $\mathrm{CaCC}$ activation are cell type specific. For example, CaCCs facilitate epithelial cell chloride secretion, modulate neuroexcitation and smooth-muscle contraction by depolarization of the plasma membrane and prevent polyspermia in oocytes. ${ }^{45} \mathrm{ClC} 1$ is a voltage-dependent chloride channel that is activated by membrane depolarization and its expression is responsible for the large chloride conductance in skeletal muscle allowing for membrane repolarization after each action potential. ${ }^{49} \mathrm{ClC} 2$ is a ubiquitously expressed, inwardly rectifying chloride channel that is activated by hyperpolarization, cell swelling and extracellular acidification. ${ }^{45}$ Two members of the $\mathrm{ClC}$ family are predominantly expressed in the kidney, $\mathrm{ClC}-\mathrm{Ka}$ and $\mathrm{ClC}-\mathrm{Kb}$. Their expression in the renal thin and thick ascending limb of Henle's loop and the inner ear provide a transcellular route for chloride reabsorption and mutations in these genes have been linked with deafness and kidney failure. ${ }^{45}$ Lastly, ligand gated chloride channels, GABA and glycine gated chloride channels, are pentameric proteins formed by the assembly of different subunits. There are four types of $\alpha\left(\alpha_{1-4}\right)$ subunits and one type of $\beta$ subunit that make up glycine gated chloride channels with the usual stoichiometry of $2 \alpha_{1}: 3 \beta$. GABA subunits are more heterogenous: $\alpha_{1-6,} \beta_{1-3,}, \gamma_{1-3}, \delta, \varepsilon, \pi, \theta$ and $\rho_{1-3}$. Thus, it can be observed that a large number of isoforms of ligand gated chloride channels can be formed from the various subunit types. Ligand gated chloride channels are excitatory in embryonic life as they induce 
depolarization and inhibitory in the developed nervous system due to the hyperpolarization it causes upon channel opening. ${ }^{45} \mathrm{~A}$ wide variety of diseases have been linked to mutations in mammalian chloride channels. However, for the purpose of this study, the recent advancements made in the field of cancer biology and role of chloride channels are discussed in the following section.

\section{Chloride channels and cancer}

Mammalian chloride channels modify cytosolic $\mathrm{Cl}^{-}$activity and mediate osmolyte flux, which are key to various cellular processes such as cell proliferation, cell cycle and apoptosis. ${ }^{50-52}$ Ion channels may affect proliferation by modulating essential homeostatic parameters such as intracellular $\mathrm{Ca} 2+, \mathrm{pH}$, cell volume, uptake of substrates, release of metabolites and playing a significant role at cell cycle checkpoints. Chloride channels are suggested to be involved in the cellular mechanisms that are required to compensate for the large volume changes that occur during the G1/S transition and around the M phase as a consequence of the metabolite accumulation in the cytoplasm or the depolymerization of the actin cytoskeleton. ${ }^{53,54}$ For example, mRNA of one of the nine chloride channel $(\mathrm{ClC})$ family members, $\mathrm{ClC} 5$, is up-regulated in $\mathrm{S}$ and $\mathrm{G} 2 / \mathrm{M}$ phases and down-regulated in G0/G1 phase in myeloid cells. ${ }^{53}$ Modulation of chloride permeability is assumed to be crucial in fibroblast cells as well as it allowed the reentry of quiescent cells into proliferating phases. ${ }^{55}$ A glioma-specific chloride current has been shown to increase significantly in early G1 and M phases and it is proposed that the cytoskeletal rearrangements required during cell division lead to the changes observed in chloride

currents. ${ }^{56}$ These findings suggest that changes in protein and mRNA expression levels of 
the various chloride channels required during cell cycle also leads to changes in dynamic functionality of chloride channels during cell cycle.

However, the balance of chloride channel function and conductivity is crucial in deciding whether the cells will undergo proliferation or the other extreme, apoptosis. If the conductance is not within the normal range, the environmental conditions leading to excessive activation of $\mathrm{Cl}$ channels may promote apoptosis. ${ }^{57}$ It has been suggested that cell death is associated with chloride influx because presence of chloride channel blockers inhibited the death and chloride influx induced by Antimycin A. ${ }^{58}$ Fas ligand mediated cell death activates outwardly rectifying chloride channel (ORCC) in Jurkat T lymphocytes and inhibition of these chloride channels by different drugs correlates with a protective effect against apoptosis in $\mathrm{T}$ lymphocytes and peripheral cells as well. ${ }^{59,60}$ Most chloride channels allow exit of $\mathrm{HCO}_{3}^{-}$, leading to cytosolic acidification, which in turn inhibits cell proliferation and leads to cell death. ${ }^{61}$ Furthermore, chloride intracellular channel 1 (CLIC1) was identified as a metastasis-associated protein since it was significantly upregulated in a highly metastatic gallbladder cancer cell line. ${ }^{62}$ It has been shown that CLCA2 (hCLCA2), a $\mathrm{Ca}(2+)$-sensitive chloride channel protein, in conjunction with alpha(6)beta(4) integrin serve as adhesion molecules that mediate colonization of the lungs by human breast cancer cells. ${ }^{63}$ Thus, these findings further strengthen that chloride channels can have dual functions of promoting apoptosis as well as proliferation, depending on the balance of expression level and conductance.

Given the essential roles of chloride channels in maintaining basic homeostatic parameters, it is not striking to find that modulating Chloride channel activity can disrupt cellular homeostasis and impair proliferation and survival. However, the mechanisms and 
downstream effectors of cell death are not fully understood. Of note, malignant cells appear more sensitive to alterations in intracellular Chloride concentration, compared to untransformed cells. The basis for this therapeutic window is unclear, but may relate to increased expression of chloride channels on the surface of malignant cells, or to increased sensitivity to Chloride channel agonists and antagonists. ${ }^{62,63}$ Malignant cells are also more sensitive to changes in cell volume, which may also explain the observed therapeutic window. ${ }^{53}$ Thus, given the recent findings that relate chloride channels with cancer pathology, we formulated the hypothesis that ivermectin induces cytotoxicity to malignant cells by activating chloride channels that lead to an increase in intracellular chloride concentration, plasma membrane hyperpolarization to induce reactive oxygen species, which would then promote cells to undergo cell death.

Thus, my main objectives were to:

1. Test the preclinical activity of ivermectin in vitro and in vivo

2. Measure chloride influx upon ivermectin treatment in sensitive and resistant cell lines

3. Measure plasma membrane potential and investigate the role of chloride in the changes seen in membrane potential

4. Measure reactive oxygen species production upon treatment and investigate the functional relevance of production of reactive oxygen species

5. Evaluate the response to ivermectin in sensitive cell lines in the presence of other agents that also induce ROS production upon treatment 


\section{MATERIALS AND METHODS}

\section{Reagents}

The compounds in the chemical library were purchased from Sigma Aldrich (St. Louis, MO). Annexin V, Propidium Iodide (PI), Indo-1 AM, 6-methoxy-N-(3-sulfopropryl) quinolinium (SPQ), carboxydichlorofluorescein diacetate (Carboxy $\mathrm{H}_{2}$ DCF-DA), bis(1,3-dibutylbarbituric acid)trimethine oxonol $\left(\mathrm{DiBAC}_{4}(3)\right.$ and 5,5',6,6'-tetrachloro1,1',3,3'-tetraethyl benzimidazolylcarbocyanine iodide (JC-1) were all purchased from (Invitrogen Canada, Burlington, Canada).

\section{Cell lines}

Human leukemia (OCI-AML2, HL60, U937, KG1a), prostate cancer cell line (DU145) and murine (MDAY-D2) leukemia cell line were maintained in RPMI 1640 medium. Media was supplemented with $10 \%$ fetal calf serum (FCS), $100 \mu \mathrm{g} / \mathrm{mL}$ penicillin and 100 units/mL of streptomycin (all from Hyclone, Logan, UT). TEX cells were maintained in IMDM, 15\% FBS, 2mM L-glutamine, 1\%, penicillin-streptomycin, $20 \mathrm{ng} / \mathrm{mL} \mathrm{SCF}$, 2ng/mL IL-3. All Cells were incubated at $37^{\circ} \mathrm{C}$ in a humidified air atmosphere supplemented with $5 \% \mathrm{CO}_{2}$.

\section{Primary cells}

Primary human acute myeloid leukemia (AML) samples were isolated from fresh bone marrow and peripheral blood samples of consenting patients. Similarly, primary normal hematopoietic cells were obtained from healthy consenting volunteers donating 
peripheral blood mononuclear cells (PBSCs) for stem cell transplantation. The mononuclear cells were isolated from the samples by Ficoll density centrifugation. Primary cells were cultured at $37^{\circ} \mathrm{C}$ in IMDM supplemented with $10 \% \mathrm{FCS}, 1 \mathrm{mM}$ of Lglutamine and appropriate antibiotics. The collection and use of human tissue for this study were approved by the University Health Network institutional review board.

\section{Chemical screen for cytotoxic compounds}

HL60, KG1a, OCI AML2 and THP1 cells were seeded into 96-well polystyrene tissue culture plates (Corning). After seeding, cells were treated with aliquots of the chemical library (=100) at increasing concentrations $(3-50 \mu \mathrm{M})$ with a final DMSO concentration of $0.05 \%$. Seventy two hours after incubation, cell growth and viability was measured by the MTS assay. Liquid handling was performed by a Biomek FX Laboratory Automated Workstation (Beckman Coulter Fullerton, CA).

\section{Cell viability assays}

Cell growth and viability was assessed by the MTS assay (Promega, Madison, WI) according to the manufacturer's instructions and as previously described. ${ }^{64}$ Cell death was measured by Annexin V-fluroscein isothiocyanate (FITC; Biovision Research Products, Mountain View, CA) staining and flow cytometry according to the manufacturer's instructions and as previously described. ${ }^{65}$

To assess clonogenic growth, primary AML cells or granulocyte colony-stimulating factor (G-CSF) mobilized PBSCs $\left(6.25 \times 10^{5} / \mathrm{mL}\right)$ were treated with ivermectin or buffer control for 24 hours. After treatment, cells were washed and equal volumes were plated 
in duplicate in MethoCult GF H4434 medium (StemCell Technologies, Vancouver, BC) containing $1 \%$ methycellulose in IMDM, 30\% FCS, $1 \%$ bovine serum albumin, $3 \mathrm{U} / \mathrm{mL}$ of recombinant human erythropoietin, $10^{-4} \mathrm{M}$ of 2-mercaptoethanol, $2 \mathrm{mM}$ of Lglutamine, $50 \mathrm{ng} / \mathrm{mL}$ of recombinant human stem cell factor, $10 \mathrm{ng} / \mathrm{mL}$ of GM-CSF, and $10 \mathrm{ng} / \mathrm{mL}$ of rh IL-3. Seven days (AML samples) or 14 days (normal PBCS) after plating, the number of colonies containing 20 or more cells was counted as previously described ${ }^{66}$ The plating efficiency of AML patients ranged from 0.5\%-6\% where as the plating efficiency of normal PBSCs were $0.1 \%$ for both BFU-E and CFU-GM.

\section{Assessment of the anticancer activity of Ivermectin in mouse models of leukemia}

MDAY-D2 murine leukemia cells, and K562 and OCI-AML2 human leukemia cells (2.5 x $10^{5}$ ) were injected subcutaneously into both flanks of sub-lethally irradiated (3.5 Gy) NOD/SCID mice (Ontario Cancer Institute, Toronto, ON). Four (OCI-AML2), five (MDAY-D2), or seven (K562) days after injection, once tumors were palpable, mice were then treated daily for 10 days (K562) or treated with 8 doses over 10 days (OCIAML2) with ivermectin $(3 \mathrm{mg} / \mathrm{kg})$ by oral gavage in water or vehicle control $(\mathrm{n}=10$ per group). MDAY-D2 mice were treated similarly but dosage escalated from $3 \mathrm{mg} / \mathrm{kg}$ (4days) to $5 \mathrm{mg} / \mathrm{kg}$ (3 days) and $6 \mathrm{mg} / \mathrm{kg}$ (3 days) as the drug was well tolerated. Tumor

volume (tumor length $\mathrm{x}$ width $^{2} \times$ 0.5236) was measured three times a week using calipers. Fourteen (MDAY-D2), 15 (OCI-AML2) or 17 (K562) days after injection of cells, mice were sacrificed, tumors excised and the volume and weight of the tumors were measured. All animal studies were carried out according to the regulations of the Canadian Council on Animal Care and with the approval of the local ethics review board. 


\section{Intracellular ion measurements}

Intracellular chloride concentration was measured using a fluorescent indicator for chloride, SPQ as previously described. ${ }^{67}$ Upon binding halide ions like chloride, SPQ is quenched resulting in a decrease in fluorescence without a shift in wavelength. After treating OCI AML2 $\left(5 \times 10^{5}\right)$ cells and DU145 $\left(4 \times 10^{5}\right)$ overnight with ivermectin (3-10 $\mu \mathrm{M})$, cells were incubated for 15 minutes with SPQ $(5 \mathrm{mM})$ at $37^{\circ} \mathrm{C}$ in a hypotonic solution (HBSS/H2O 1:1) to promote the intracellular uptake of SPQ. After 15 minutes of incubation with SPQ, cells were diluted 15:1 in HBSS and centrifuged. The supernatant was removed, cells were resuspended in 200uL of fresh HBSS and incubated for 15 minutes in $37^{\circ} \mathrm{C}$ to allow recovery from the hypotonic shock. Cells were then stained with propidium iodide and SPQ fluorescence in the PI negative cells was determined using an LSR-II flow cytometer (Beckton Dickonson, San Jose, CA) (excitation $.351 .1 \mathrm{~nm}$, emission $485 \mathrm{~nm}$ ). Results were analyzed with FlowJo version 8.8 (TreeStar, Ashland, OR).

Changes in cytosolic calcium concentration were detected with the fluorescent dye, Indo1 AM (final concentration $6 \mu \mathrm{M}$ ) as previously described. ${ }^{68}$

\section{Determination of plasma membrane potential}

Plasma membrane potential was measured as previously described. ${ }^{69}$ Briefly, cells treated with ivermectin or buffer control in RPMI, chloride replete medium (140 mM sodium chloride, $5 \mathrm{mM}$ potassium chloride, $1 \mathrm{mM}$ magnesium sulfate, $1.8 \mathrm{mM}$ calcium acetate, $10 \mathrm{mM}$ glucose, $10 \mathrm{mM}$ HEPES and $0.1 \%(\mathrm{wt} / \mathrm{v}) \mathrm{BSA}$ ), or chloride free media where equimolar gluconate salts of sodium and potassium replaced the sodium chloride in the 
chloride replete medium. After incubation, cells were stained with $\operatorname{DiBAC}_{4}(3)$ (final concentration $30 \mathrm{nM}$ ) and fluorescence determined by flow cytometry (BD FACS Canto, Beckton Dickonson, San Jose, CA) (excitation $=488 \mathrm{~nm}$, emission $=516 \mathrm{~nm})$ Analysis was conducted using FACSDiva Software (BD Biosciences).Calibration curves were prepared using phosphate buffers with varying potassium ion concentrations as previously described. ${ }^{70}$

\section{Calibration curves}

To measure plasma membrane potential, calibration curves were prepared using ten phosphate buffers, each with varying potassium ion concentrations, as described by Rothbard et al. (2004). Briefly, each buffer contained a different potassium concentration and with potassium isotonically replacing sodium at high concentrations. Cells plated in RPMI $+10 \%$ FCS were washed once with PBS and then incubated with the various phosphate buffer solutions. After a $30 \mathrm{~min}$ incubation at $37^{\circ} \mathrm{C}$ for 20 minutes, $3 \mu \mathrm{L}$ of $100 \mathrm{uM}$ bis-(1,3-dibutylbarbituric acid)trimethine oxonol $\left(\mathrm{DiBAC}_{4}(3)\right.$, Invitrogen, 30nM final volume) was added. This was allowed to incubate for $30 \mathrm{~min}$ and then cells were washed with $1 \mathrm{~mL}$ of their respective buffer to remove excess $\operatorname{DiBAC}_{4}(3)$. Cells were then resuspended in $300 \mathrm{uL}$ of their phosphate buffers and read on a BD FACS Canto (excitation $=488 \mathrm{~nm}$, emission $=516 \mathrm{~nm}$ ). Analysis was conducted using FACSDiva Software (BD Biosciences).

To measure mitochondrial membrane potential, cells were treated with ivermectin similarly as described above and then washed twice with PBS and incubated with $2 \mu \mathrm{M}$ of 5,5',6,6'-tetrachloro-1,1',3,3'-tetraethyl benzimidazolylcarbocyanine iodide (JC-1, Invitrogen) for 20 minutes at $37^{\circ} \mathrm{C}$. Each sample was then washed twice with $1 \mathrm{~mL}$ PBS 
and resuspended in $300 \mu \mathrm{L}$ PBS prior to being read on a BD FACS Canto. Samples were excited at $488 \mathrm{~nm}$ and emission was collected at 526nm (green) and 595nm (red). Analysis was conducted using FACSDiva Software (BD Biosciences). To obtain the mitochondrial membrane potential (red/green), emission from the red channel was divided by emission from the green channel.

\section{Detection of Reactive oxygen species}

Intracellular Reactive oxygen species (ROS) were detected by staining cells with Carboxy- $\mathrm{H}_{2}$ DCFDA (final concentration $10 \mu \mathrm{M}$ ) and flow cytometric analysis as previously described. ${ }^{71}$ Cells were treated with ivermectin, cytarabine and daunorubicin overnight and stained with Carboxy- $\mathrm{H}_{2}$ DCFDA in PBS buffer at $37^{\circ} \mathrm{C}$ for 30 minutes and simultaneously, cells were stained with propidium iodide to identify viable cells and assess their reactive oxygen intermediate levels. Data were analyzed with FlowJo version 8.8 (TreeStar, Ashland, OR).

\section{Drug combination studies}

The combination index (CI) was used to evaluate the interaction between ivermectin and cytarabine or daunorubicin. OCI-AML2 cells were treated with increasing concentrations of ivermectin, cytarabine and daunorubicin. Seventy-two hours after incubation cell viability was measured by the MTS assay. The Calcusyn median effect model was used to calculate the CI values and evaluate whether the combination of ivermectin with cytarabine or daunorubicin was synergistic, antagonistic or additive. CI 
values of $<1$ indicate synergism, CI $=1$ indicate additivity and CI $>1$ indicate antagonism. $^{72}$ 


\section{RESULTS}

\section{Attributions}

I would like to acknowledge all those who have contributed to this project and helped us elucidate the mechanism by which ivermectin exerts its cytotoxic effect in malignant cells.

I would like to thank the following individuals for their help:

- Marko Skrtic for helping me assess the cytotoxicity of ivermectin in a panel of leukemia cell lines in vitro and measuring viability of cells when ivermectin is combined with other drugs (Figure 1B and Figure 6C, D)

- Marcela Gronda for the clonogenic growth assays (Figure 1D)

- XioMing Wang for carrying out the in vivo experiments and testing the efficacy ivermectin in vivo (Figure 2)

- Sonali Fonesca from our collaborator, Shana Kelly's lab, for helping me with measuring the membrane potential in sensitive cell lines (Figure 3D, E, F)

- Mahadeo Sukhai and Joyce Sun for helping me assess the functional relevance of ROS in the cytotoxicity of ivermectin (Figure 5C) 


\section{A chemical screen identifies ivermectin with potential anti- cancer activity}

Off-patent and on-patent drugs with previously unrecognized anti-cancer activity can be rapidly repurposed for this new indication given their prior toxicology and pharmacology testing. To identify such compounds, we compiled a small chemical library $(n=100)$ focused on anti-microbials and metabolic regulators with wide therapeutic windows and well understood pharmacokinetics. We then treated OCIAML2, HL60, and KG1a leukemia cell lines with aliquots of this chemical library at five concentrations $(3-50 \mu \mathrm{M})$. Seventy-two hours after incubation, cell growth and viability was measured by the MTS assay. From this screen, we identified ivermectin that reduced cell viability in all cell lines in the screen with an IC50 $<10 \mu \mathrm{M}$. The results for the screen of OCI-AML2 cells with compounds added at a final concentration of $6 \mu \mathrm{M}$ is shown in Figure 1A.

\section{Ivermectin is cytotoxic to malignant cell lines and primary patient samples}

Having identified ivermectin in our chemical screens, we tested the effects of ivermectin on cell growth and viability in a panel of leukemia, cell lines. Cells were treated with increasing concentrations of ivermectin and 72 hours after incubation, cell growth and viability was assessed by the MTS assay. Ivermectin decreased the viability of the of the tested leukemia cell lines with an LD50 of approximately $5 \mu \mathrm{M}$ (Figure 1B). The loss of viability was detected at 24 hours after treatment in a time dependent manner and cell death was confirmed by Annexin V and PI staining (data not shown). 
Given the cytotoxicity of ivermectin towards leukemia cell lines, we compared its cytotoxicity to normal hematopoietic cells. Primary normal hematopoietic cells, acute myeloid leukemia patient samples and a leukemia cell line, U937, were treated for 48 hours with increasing concentrations of ivermectin. After incubation, cell viability was measured by Annein V staining. Ivermectin did not induce cell death in the peripheral blood stem cells from normal donors at concentrations up to $20 \mu \mathrm{M}$. In contrast, it remained cytotoxic to leukemia cell line and patient samples at low micromolar concentrations in these assays (Fig 1C). Ivermectin was also evaluated in clonogenic growth assays in primary AML and normal hematopoietic cells. Ivermectin $(6 \mu \mathrm{M})$ reduced clonogenic growth by $\geq 40 \%$ in $3 / 6$ primary AML samples (Figure 1D). In contrast, it was less toxic to normal hematopoetic cells with $<15 \%$ reduction in clonogenic growth in $3 / 3$ samples of normal hematopoietic mononuclear cells treated with the same concentration of ivermectin. (Figure 1D). 
Figure 1: Screen of off-patent drugs identifies antiparasitic agent ivermectin that reduces viability of malignant cells in vitro.

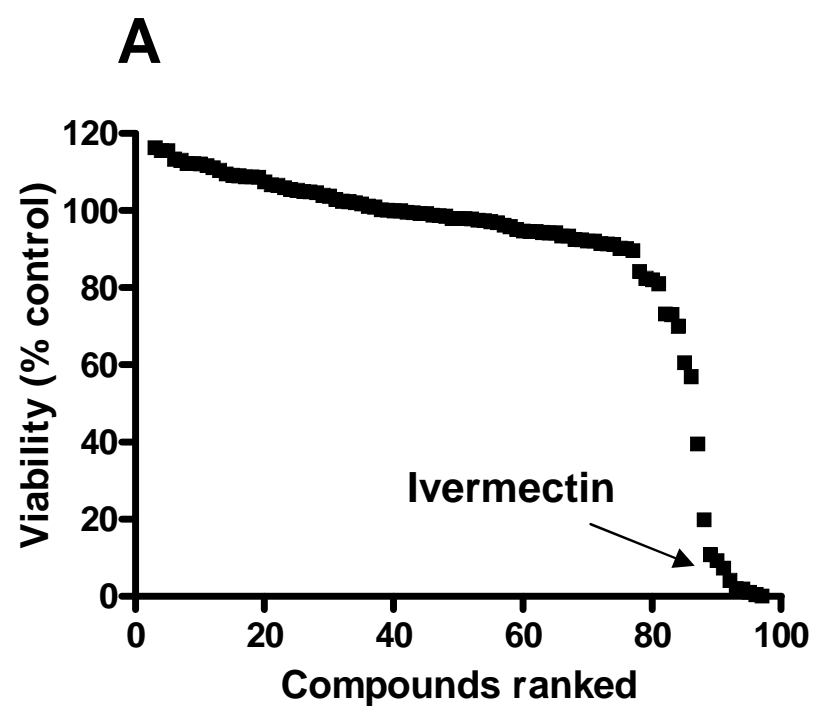

B

\begin{tabular}{|cccc|}
\hline $\begin{array}{c}\text { Cancer } \\
\text { type }\end{array}$ & Cell line & $\begin{array}{c}\text { IC50 } \\
\text { (uM) }\end{array}$ & 95\% Cl \\
\hline Leukemia & AML-2 & 4.54 & $4.25-4.84$ \\
Leukemia & HL60 & 4.64 & $4.17-5.16$ \\
Leukemia & U937 & 6.54 & $5.81-7.35$ \\
Leukemia & KG1a & 5.68 & $4.94-6.53$ \\
Leukemia & TEX & 5.41 & $4.07-7.18$ \\
\hline
\end{tabular}

Figure 1: (A) A high throughput screen with a small chemical library $(n=100)$ focused on anti-microbials and metabolic regulators with wide therapeutic windows and well understood pharmacokinetics identified ivermectin as a potential anti-cancer agent. OCIAML2 cells were incubated with aliquots of this chemical library at five concentrations $(3-50 \mu \mathrm{M})$ and viability was measured using MTS assay after 72 hours as described in the Methods and Materials section. Data represent the percentage of viable OCI AML2 cells (y axis) and the compounds $(6 \mu \mathrm{M})$ sorted in increasing potency (x axis).

(B) Leukemia cell lines were treated with increasing concentrations of ivermectin. Seventy two hours after incubation, cell growth and viability was measured by the MTS assay. Data represent the mean IC50 and 95\% CI from 3 independent experiments. 


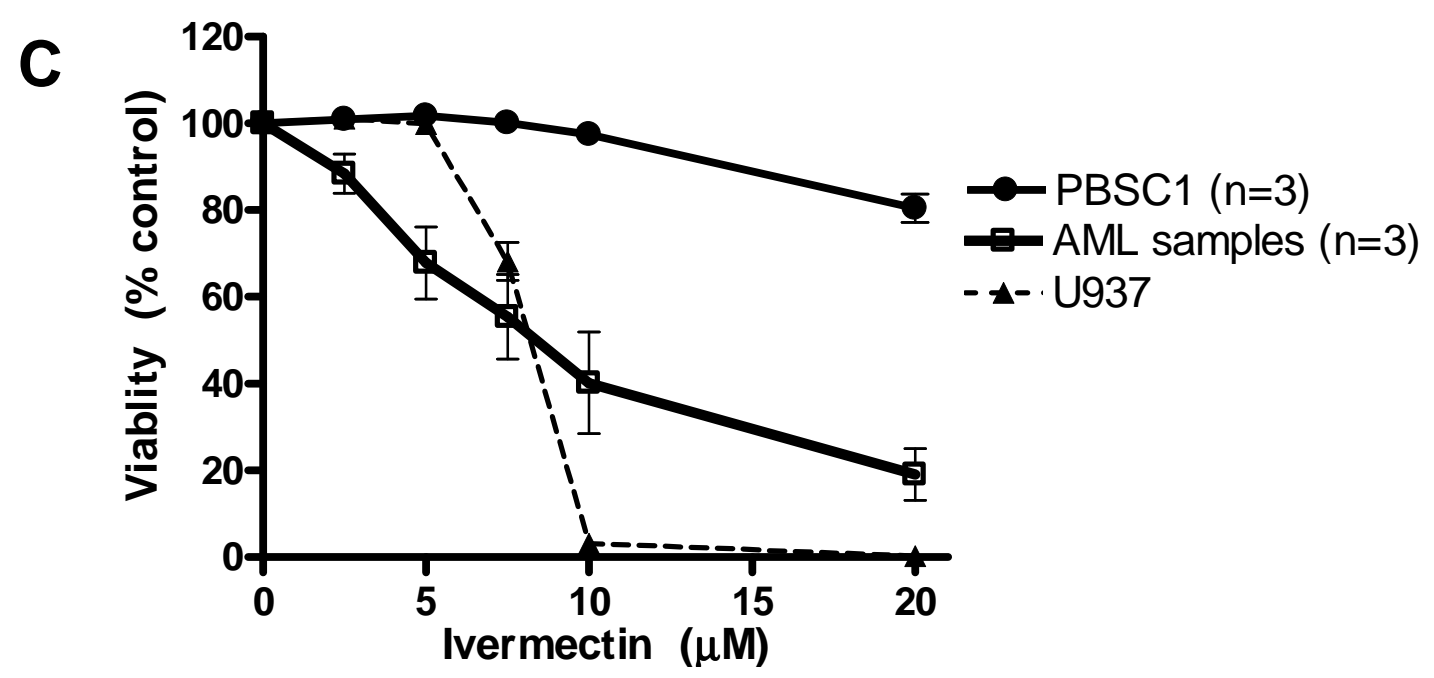

D
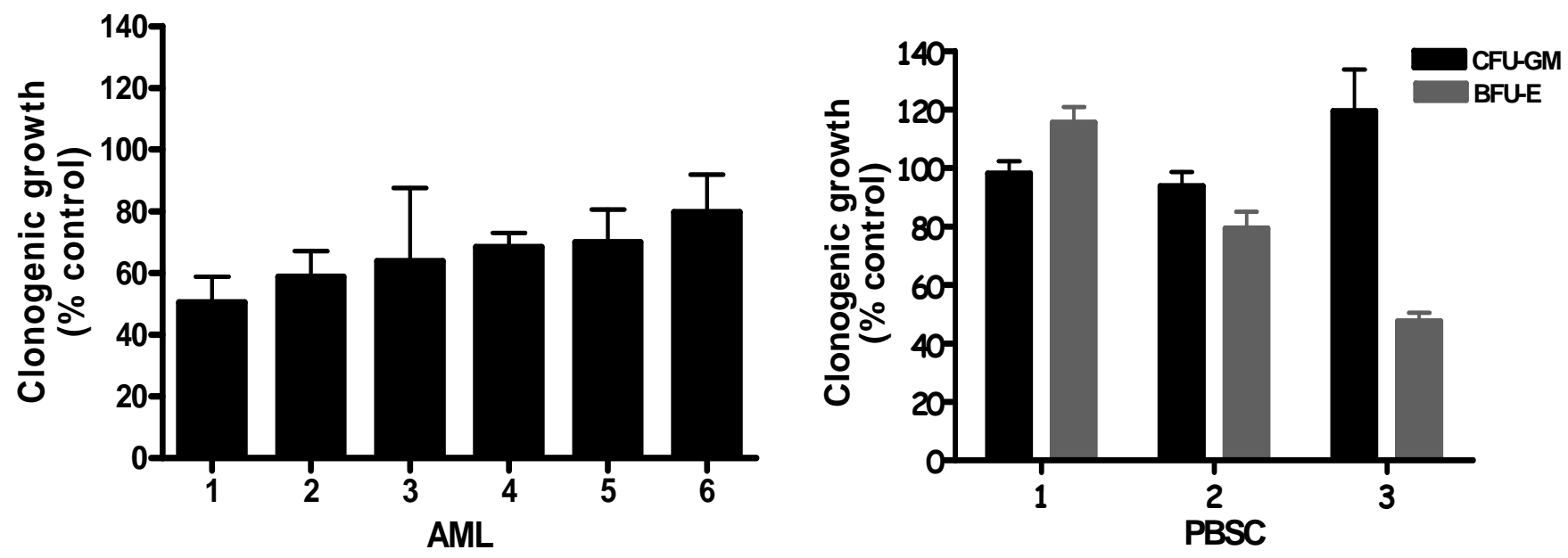

(C) Primary normal hematopoietic cells $(n=3)$, leukemia patient samples $(n=3)$ and a leukemia cell line, U937, were treated with increasing concentrations of ivermectin for 48 hours. After incubation, cell viability was measured by Annexin V and PI staining. Data represent the mean percent viable cells and SD for each of the values is also shown.

(D) Primary AML cell samples $(n=6)$ and normal samples $(n=3)$ were plated in a methylcellulose colony forming assay with ivermectin $(6 \mu \mathrm{M})$. Colonies were counted seven days (AML samples) or 14 days (normal PBSC) after plating and normalized to cultures treated with buffer alone. Data represent the mean percent colony formation compared to control and their SD values are also illustrated. 


\section{Ivermectin delays tumor growth in mouse models of leukemia}

Given the effects of ivermectin as a potential anti-leukemic agent, we evaluated ivermectin in mouse models of leukemia. Leukemia cells (MDAY-D2, OCI-AML2 and K562) were injected subcutaneously into the flank of NOD/SCID mice. Four (OCIAML2), five (MDAY-D2), or seven (K562) days after injection, once tumors were palpable, mice were then treated daily for 10 days (K562) or treated with 8 doses over 10 days (OCI-AML2) with ivermectin $(3 \mathrm{mg} / \mathrm{kg})$ by oral gavage in water or vehicle control ( $\mathrm{n}=10$ per group). MDAY-D2 mice $(\mathrm{n}=10$ per group) were treated similarly but dosage escalated from $3 \mathrm{mg} / \mathrm{kg}$ (4 days) to $5 \mathrm{mg} / \mathrm{kg}$ (3 days) and $6 \mathrm{mg} / \mathrm{kg}$ (3 days) as the drug was well tolerated. Tumor volume and weight was measured over time. Compared to buffer control, oral ivermectin significantly $(\mathrm{p}<0.05)$ decreased tumor weight and volume in all 3 models (Figure 2A-E) by up to $70 \%$ without any gross organ toxicity. Of note, a dose of $3 \mathrm{mg} / \mathrm{kg}$ in mice translates to a dose of $0.24 \mathrm{mg} / \mathrm{kg}$ in humans based on scaling of body weight and surface area and appears readily achievable based on prior studies. ${ }^{30,32}$ Thus, the activity in the xenograft studies indicates that a therapeutic window may be achievable. 
Figure 2: Ivermectin delays tumor growth and reduces tumor weight in leukemia mouse xenografts

A

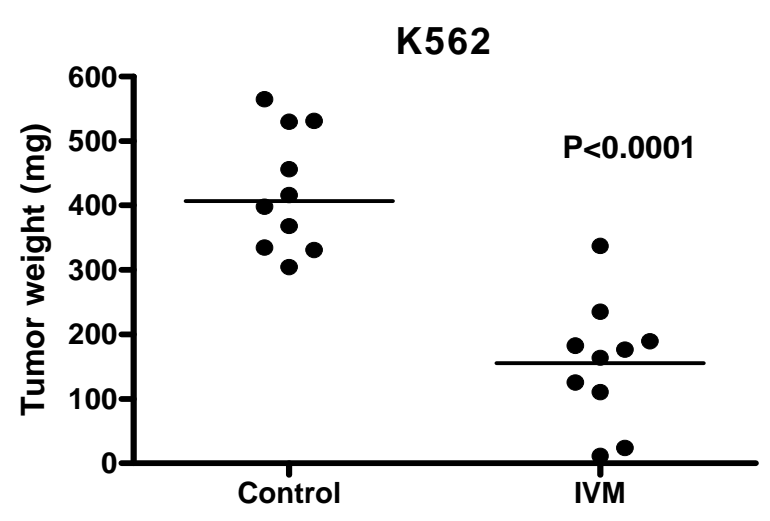

C

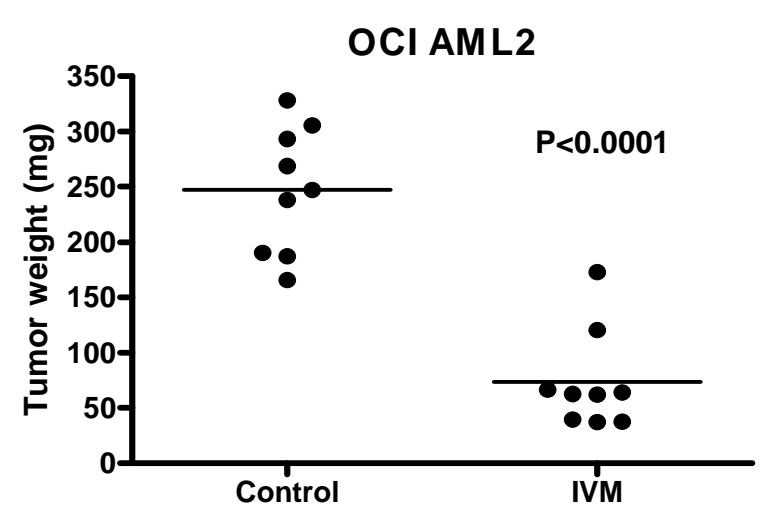

B

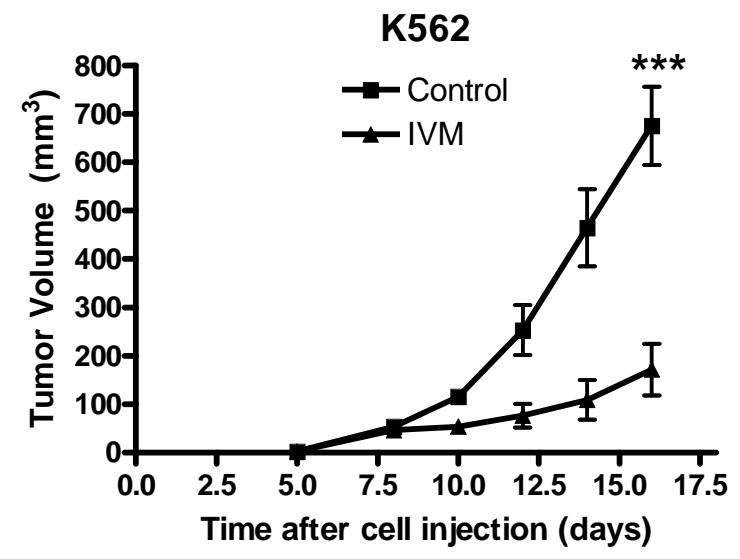

D

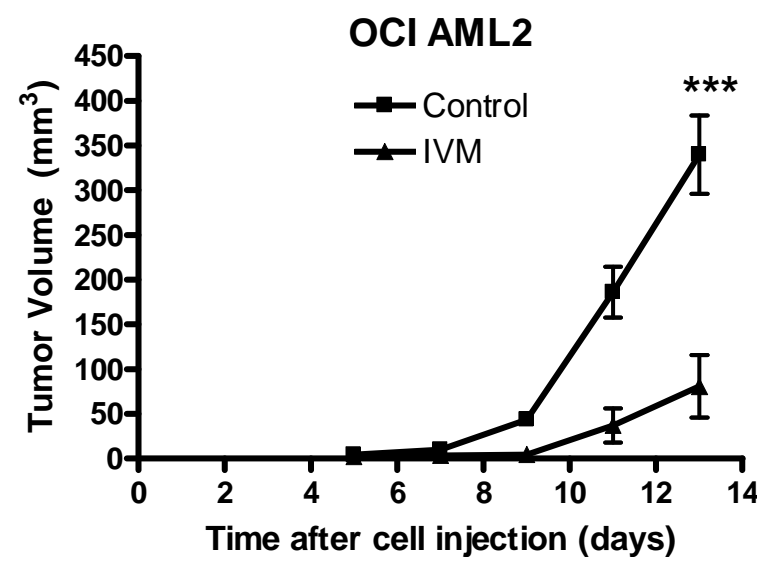


E

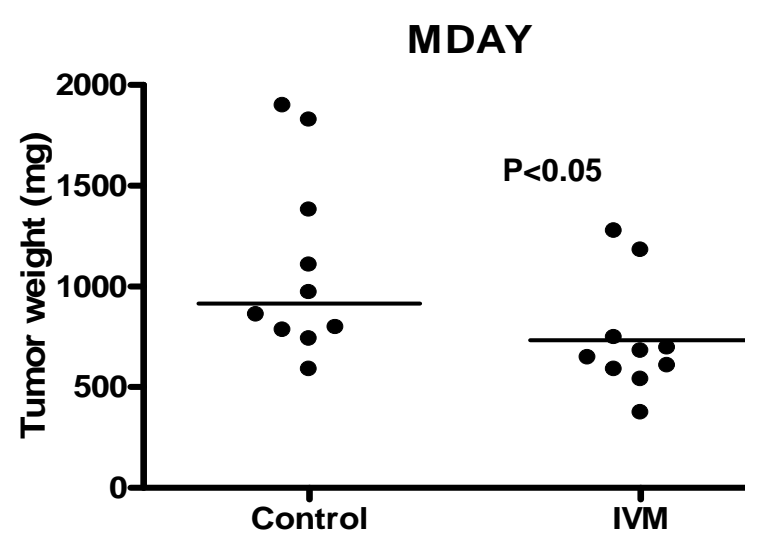

$\mathbf{F}$

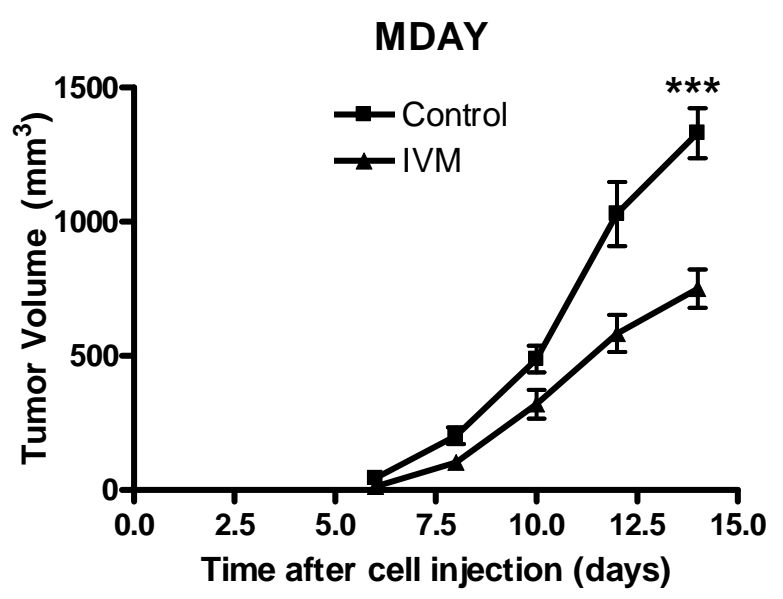

Figure 2. Sublethally irradiated NOD/SCID mice were injected subcutaneously with K562 cells ( $\mathrm{n}=20 ; 10$ per group) (A,B), OCI-AML2 human leukemia cells $(\mathrm{n}=20 ; 10$ per group) (C,D) or MDAY-D2 murine leukemia cells $(\mathrm{n}=20 ; 10$ per group) (E,F). After implantation, mice were treated with ivermectin daily for 10 days (K562) or treated with 8 doses over 10 days (OCI-AML2) with ivermectin $(3 \mathrm{mg} / \mathrm{kg}$ ) by oral gavage in water or vehicle control. MDAY-D2 mice were treated similarly but dosage escalated from $3 \mathrm{mg} / \mathrm{kg}$ (4days) to $5 \mathrm{mg} / \mathrm{kg}$ (3 days) and $6 \mathrm{mg} / \mathrm{kg}$ (3 days) as the drug was well tolerated. Fourteen (MDAY-D2), 15 (OCI-AML2) or 17 (K562) days after injection of cells, mice were sacrificed, tumors excised and the volume and weight of the tumors were measured. The tumor weight and the mean volume \pm SEM are shown. Differences in tumor volume and weight were analyzed by an unpaired t-test: $* * * p<0.0001 ; * * p<0.001 ; *^{*}<<0.05$. 


\section{Ivermectin induces intracellular chloride flux and hyperpolarization of the plasma membrane}

As an antiparasitic agent, ivermectin activates chloride channels in nematodes, causing an influx of chloride ions into the cells of the nematodes. ${ }^{73}$ Thus, we investigated whether ivermectin caused a similar influx of chloride ions into OCI-AML2 cells leukemia cells, where ivermectin induced cell death after 24 hours of treatment, and DU145 cells, that were more resistant to ivermectin induced cell death (Fig 3A). OCI AML2 and DU145 cells were treated with $10 \mu \mathrm{M}$ ivermectin for 4 hours and levels of intracellular chloride were measured by staining cells with the fluorescent dye SPQ that is quenched upon binding chloride. In OCI-AML 2 cells, ivermectin at concentrations that induced cell death but at times that preceded cell death, decreased SPQ fluorescence, consistent with an increase in levels of intracellular chloride (Figure 3B). In contrast, chloride influx was not observed in DU145 cells that were resistant to $10 \mu \mathrm{M}$ ivermectin (Figure 3C).

In nematodes, increases in intracellular chloride after ivermectin treatment cause membrane hyperpolarization. Therefore, we evaluated the effects of ivermectin on plasma and mitochondrial membrane polarization in leukemia cells. OCI-AML2 cells were treated with increasing concentrations of ivermectin. At increasing times after incubation, plasma membrane potential was measured by staining cells with DiBAC4(3) and flow cytometry. Treatment with ivermectin induced membrane hyperpolarization in a dose-dependent manner (Fig 3D) and as early as after 1 hour of treatment (Fig 3E), consistent with the influx of intracellular chloride and the effects observed in nematodes. 
In contrast to the effects on the plasma membrane, treatment with up to $6 \mu \mathrm{M}$ of ivermectin for 24 hours did not alter mitochondrial membrane potential (data not shown).

To determine whether the plasma membrane hyperpolarization observed after ivermectin treatment was related to increased chloride ion flux, we measured plasma membrane polarization after treating cells with ivermectin in buffers with and without chloride. OCI AML2 cells were treated for 5 hours with ivermectin $(6 \mu \mathrm{M})$ in a chloride replete buffer or a chloride deplete buffer where the sodium and potassium chloride ions were replaced with equimolar gluconate salts of sodium and potassium. When added to cells in the choride replete buffer, ivermectin induced plasma membrane hyperpolarization similar to cells treated in RPMI medium. However, when added to cells in chloride deplete buffer, ivermectin caused plasma membrane depolarization (Figure 3F). Thus, the effects of ivermectin on plasma membrane polarization appear to be related to increased chloride flux. 
Figure 3: Ivermectin induced a chloride influx and hyperpolarization of the plasma membrane
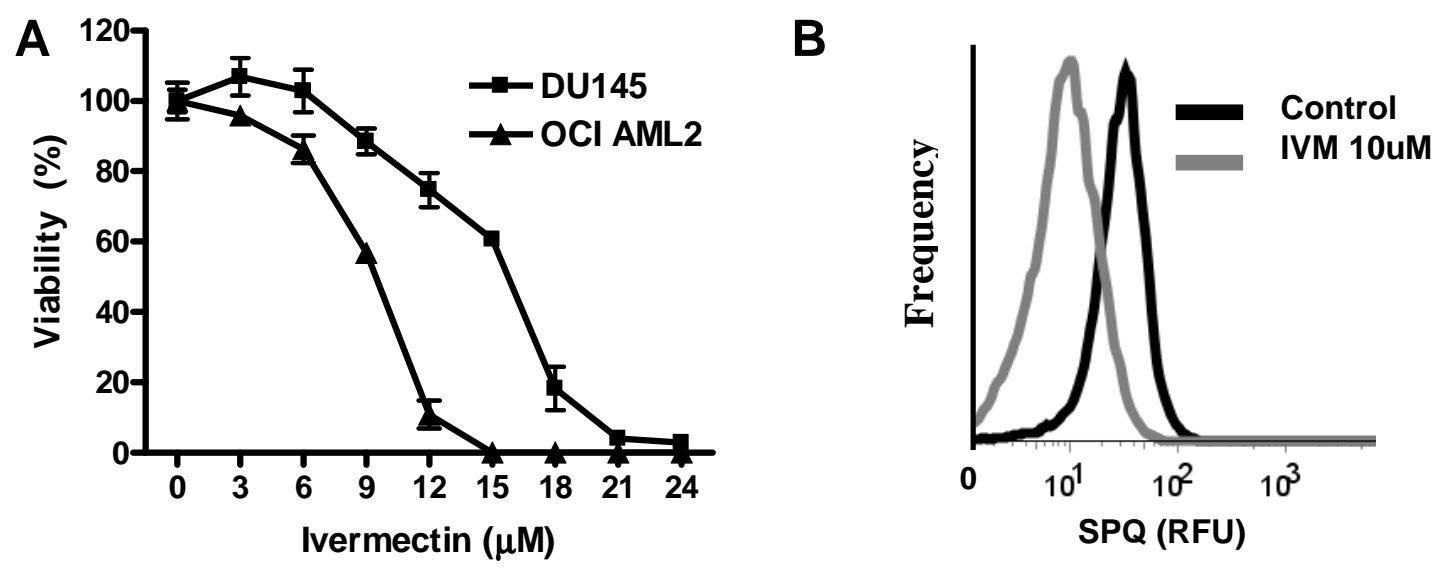

C
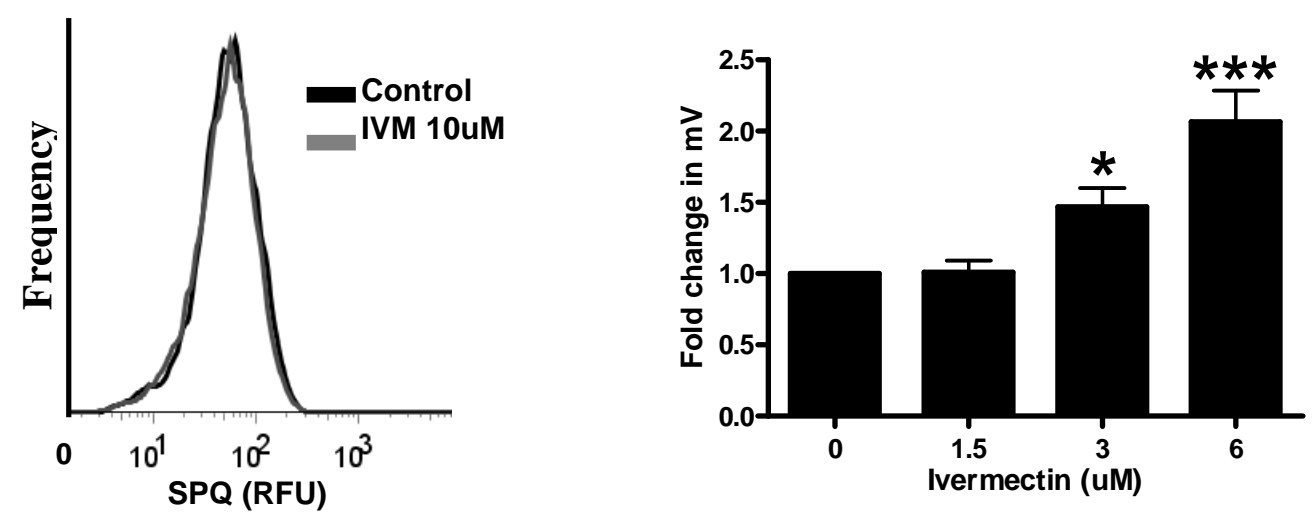


\section{$\mathbf{E}$}

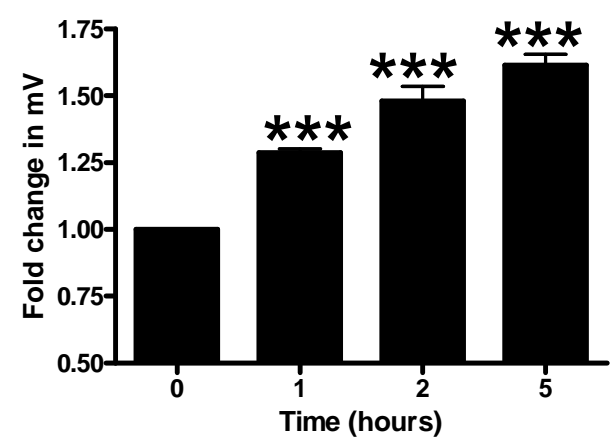

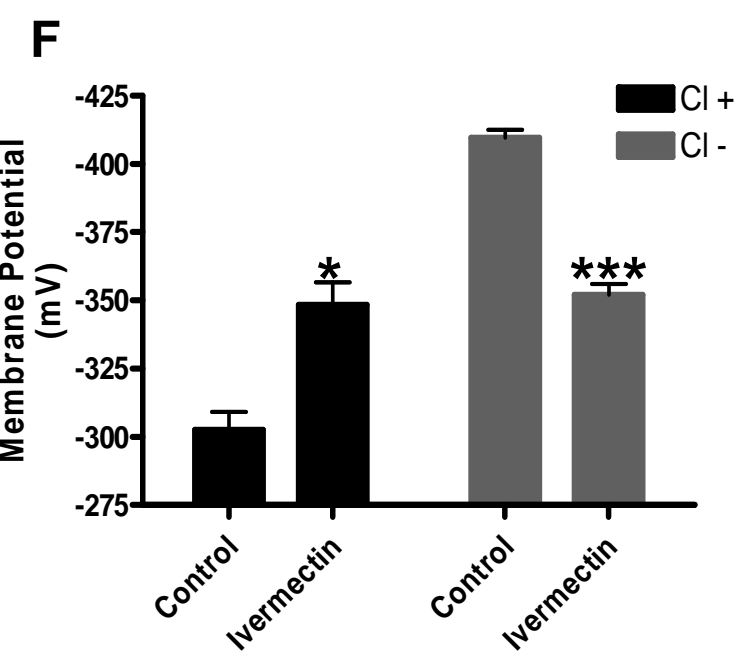

Figure 3. (A) OCI AML2 leukemia and DU145 prostate cancer cells were treated with increasing concentrations of ivermectin. After 24 hours of incubation, cell viability was measured by Annexin V and PI staining. Data represent the mean percent viable cells along with their SD (B) OCI AML2 and (C) DU145 cells were treated with $10 \mu \mathrm{M}$ ivermectin and levels of intracellular chloride were measured by staining cells with the fluorescent dye SPQ that is quenched upon binding chloride. Representative histograms are shown.

OCI-AML2 cells were treated with increasing concentrations of ivermectin for 24 hours (D) or $6 \mu \mathrm{M}$ of ivermectin for increasing times of incubation (E). After treatment, plasma membrane potential was measured by staining cells with DiBAC4(3) and flow cytometry. Data represent the mean fold change in plasma membrane potential compared to control treated cells and SD is also illustrated. Representative experiments performed in triplicate are shown. Differences in fold change of membrane potential compared to control were analyzed by an unpaired t-test: *** $\mathrm{p}<0.0001 ; * \mathrm{p}<0.05$. (F) OCI AML2 cells were treated with $6 \mu \mathrm{M}$ ivermectin in chloride replete and chloride free media for 5 hours. After incubation, plasma membrane hyperpolarization was measured as above. Data represent the mean plasma membrane potential with their SD. Representative experiments performed in triplicate are shown. Differences in membrane potential compared to control were analyzed by an unpaired t-test: $* * * p<0.0001 ; * \mathrm{p}<0.05$. 


\section{Ivermectin increases intracellular calcium but is not functionally}

important in leukemia cells

Plasma membrane hyperpolarization can lead to calcium influx ${ }^{74}$. Therefore, we tested the effects of ivermectin on calcium influx in leukemia cells. OCI-AML2 cells were treated with ivermectin and the concentration of intracellular calcium was measured by staining cells with the ratiometric dye, Indo-1 AM. As a positive control, cells were treated with digoxin which is known to increase intracellular calcium. ${ }^{75,76}$ Similar to the effects of digoxin, ivermectin increased intracellular calcium (Figure 4A, B). However, the increase in intracellular calcium did not appear sufficient to explain the cytotoxicity of ivermectin, because chelation of intra and extracellular calcium with BAPTA-AM and EDTA, respectively, did not inhibit ivermectin-induced cell death (data not shown). 
Figure 4: Ivermectin induces a calcium influx in OCI AML2 cells.
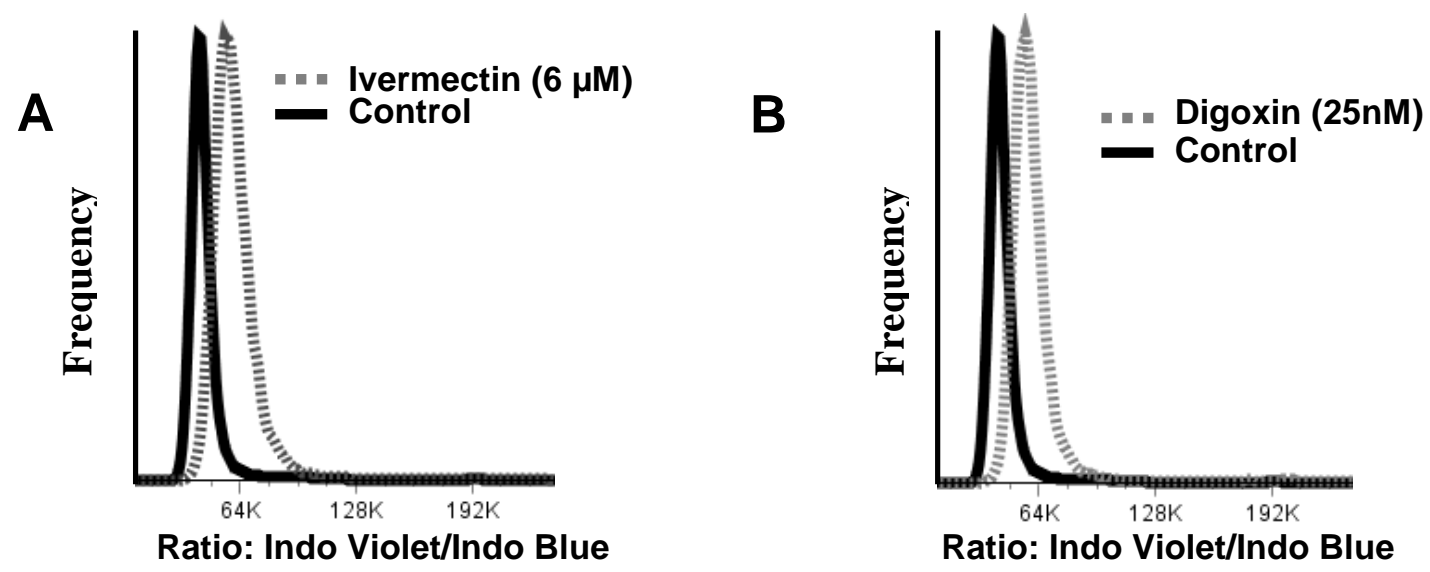

Figure 4. (A) OCI-AML 2 cells were treated with ivermectin $(6 \mu \mathrm{M})$. After 5 hours of treatment, cytosolic calcium concentration was detected by staining with the fluorescent dye, Indo-1 AM and flow cytometry. As a control for cytosolic calcium influx, OCIAML2 cells were treated with digoxin $(25 \mathrm{nM})$ for 5 hours (B). Representative histograms are shown. 


\section{Ivermectin increases intracellular reactive oxygen species}

Manganese chloride, cobalt chloride and mercuric chloride can lead to generation

of reactive oxygen species (ROS) ${ }^{77-79}$ Therefore, we tested whether ivermectin increased ROS production in leukemia cells due to the observed chloride influx. OCI-AML2 cells were treated with ivermectin at increasing concentrations and times of incubation. After treatment, levels of intracellular ROS were measured by staining cells with Carboxy$\mathrm{H}_{2}$ DCFDA and flow cytometry. Treatment with ivermectin increased ROS production at times and concentrations that coincided with plasma membrane hyperpolarization (Figure $5 \mathrm{~A}, \mathrm{~B})$.

To determine whether the increased ROS production was functionally important for ivermectin-induced cell death, cells were treated with ivermectin along with the free radical scavenger N-acetyl-L-Cysteine (NAC). NAC abrogated ivermectin-induced cell death, consistent with a mechanism of cell death related to ROS production and keeping with its effects on plasma membrane hyperpolarization and chloride influx (Figure 5C). 


\section{Figure 5: Ivermectin induces generation of reactive oxygen species.}

A
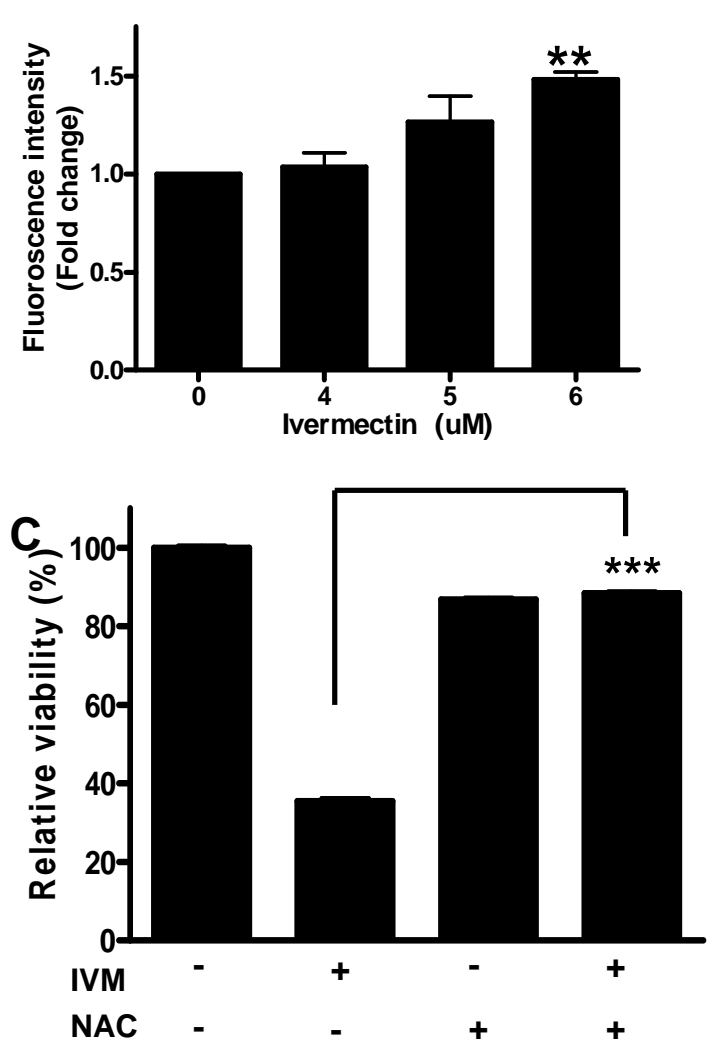

B

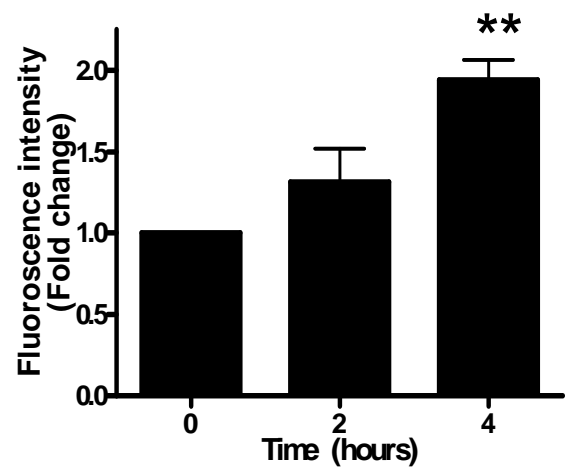

Figure 5. OCI-AML 2 leukemia cells were treated with increasing concentrations of ivermectin for over night (A) or $6 \mu \mathrm{M}$ of ivermectin for increasing times of incubation (B). After incubation, intracellular Reactive oxygen (ROS) species were detected by staining cells with Carboxy-H2DCFDA (final concentration $10 \mu \mathrm{M}$ ) and flow cytometric analysis. Data represent the mean fold change and their SD in ROS production compared to control. Representative experiments performed in triplicate are shown.

(C) OCI AML2 cells were treated with ivermectin $(3 \mu \mathrm{M})$, the ROS scavenger, N-acetylL-Cystein (NAC) $(5 \mu \mathrm{M})$ or the combination of NAC with ivermectin. After 48 hours of treatment, cell growth and viability were measured by the MTS assay. The mean percent viable cells from a representative experiment performed in triplicate are shown and their $\mathrm{SD}$ is also illustrated. 


\section{Ivermectin synergizes with cytarabine and daunorubicin}

Cytarabine and daunorubicin are used in the treatment of AML and increase ROS production through mechanisms related to DNA damage (Figure 6A, B) ${ }^{80,81}$ Therefore, we evaluated the combination of ivermectin with cytarabine and daunorubicin. OCI AML2 cells were treated with increasing concentrations of ivermectin alone and in combination with cytarabine and daunorubicin. Cell growth and viability was measured 72 hours after incubation using the MTS assay. Data were analyzed by the Calcusyn median effect model where the combination index (CI) indicates synergism $(\mathrm{CI}<0.9)$, additively $(\mathrm{CI}=0.9-1.1)$ or antagonism $(\mathrm{CI}>1.1)$. The combination of ivermectin and cytarabine demonstrated strong synergism with $\mathrm{CI}$ values at the $\mathrm{ED}_{25}, \mathrm{ED}_{50}$ and $\mathrm{ED}_{75}$ of $0.51,0.58$ and 0.65 , respectively. Likewise the combination of ivermectin and daunorubicin was also synergistic with $\mathrm{CI}$ values at the $\mathrm{ED}_{25}, \mathrm{ED}_{50}$ and $\mathrm{ED}_{75}$ of 0.48 , 0.51 and 0.54 , respectively. We also evaluated the combination of ivermectin with the antihelmintic albendazole as this agent synergized with ivermectin for treatment of

nematodes. ${ }^{82,83}$ In contrast to the synergy observed with cytarabine and daunorubicin, albendazole antagonized the anti-leukemic effects of ivermectin with CI values at the $\mathrm{ED}_{25}, \mathrm{ED}_{50}$ and $\mathrm{ED}_{75}$ of $1.59,1.09$ and 0.89 , respectively. 


\section{Figure 6: Ivermectin synergizes with cytarabine and daunorubicin to induce cell death in leukemia cells.}
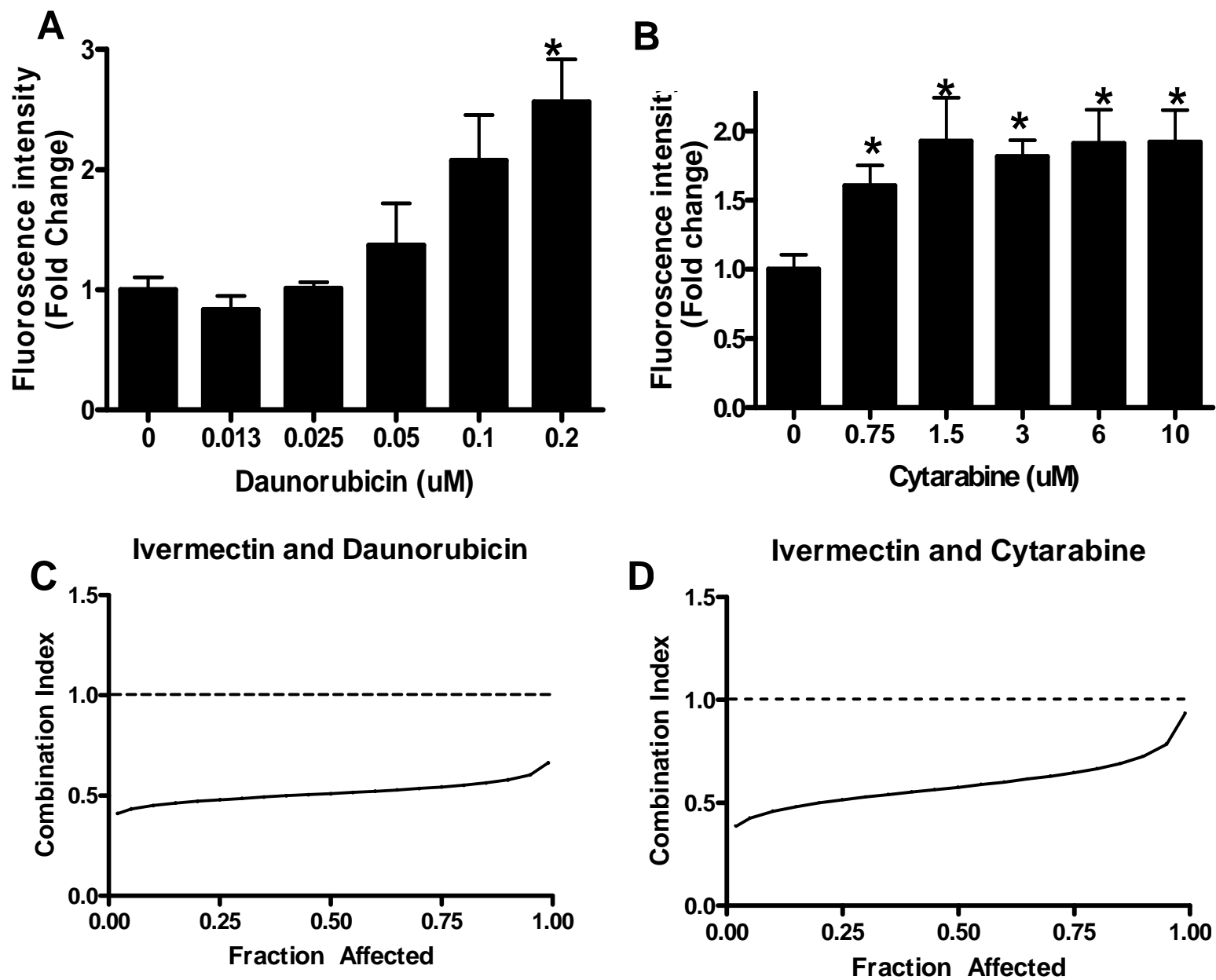

Figure 6. OCI-AML2 cells were treated with increasing concentrations of daunorubicin (A) and cytarabine (B) for overnight. After treatment, ROS production was measured by staining cells Carboxy- $\mathrm{H}_{2}$ DCFDA (final concentration $10 \mu \mathrm{M}$ ) and flow cytometric analysis. Data represent the mean fold change in ROS production compared to control and their SD is also shown. Representative experiments performed in triplicate are shown.

The effects of different concentrations of ivermectin in combination with cytarabine and daunorubicin on the viability of OCI-AML2 cells were measured by MTS assay after 72 hours of incubation. Data were analyzed with Calcusyn software as described in Materials and Methods. Combination index (CI) versus Fractional effect (Fa) plot showing the effect of the combination of ivermectin with daunorubicin (C) and ivermectin with cytarabine (D). CI $<1$ indicates synergism. Representative isobolograms of experiments performed in triplicate are shown. 


\section{DISCUSSION}

To identify known drugs with previously unrecognized anti-leukemia activity, we compiled and screened a library of off-patent and on-patent drugs for compounds cytotoxic to leukemia cells. From this screen we identified the anti-parasitic agent, ivermectin, which induced cell death in leukemia cell lines at low micromolar concentrations and delayed tumor growth in mouse models of leukemia at doses as low as $3 \mathrm{mg} / \mathrm{kg}$.

As part of its development as an anti-parasitic, the pharmacology and toxicology of ivermectin has been studied extensively in humans and animals. For example, healthy male volunteers received a $14 \mathrm{mg}$ capsule of radiolabelled ivermectin. The mean Tmax was 6 hours with a half-life of 11.8 hours. Ivermectin is metabolized in the liver, ivermectin and/or its metabolites are excreted almost exclusively in the feces over an estimated 12 days, with $<1 \%$ of the administered dose excreted in the urine. ${ }^{31}$ In onchocerciasis patients following a single oral dose of $150 \mu \mathrm{g} / \mathrm{kg}$, the maximum plasma concentration was $52.0 \mathrm{ng} / \mathrm{ml}$, achieved in 5.2 hours with an area under the curve over 48 hours of $2852 \mathrm{ng} . \mathrm{h} / \mathrm{ml}(3 \mu \mathrm{M}){ }^{84}$

Likewise, the toxicology of ivermectin in humans and animals is well described and suggests the doses of the drug required for an anti-tumor effect can be achieved in humans. For example, the $\mathrm{LD}_{50}$ of oral ivermectin is approximately $28-30 \mathrm{mg} / \mathrm{kg}$ in mice, $80 \mathrm{mg} / \mathrm{kg}$ in dogs and above $24 \mathrm{mg} / \mathrm{kg}$ in monkeys. ${ }^{28,84}$ Humans, being treated for onchocerciasis typically receive a single low dose of $100-200 \mu \mathrm{g} / \mathrm{kg}$ of ivermectin is administered as a single dose, but higher doses for longer durations have been used to treat other conditions. When used to treat onchocerciasis, hypotension, fever, adenitis, 
arthralgia, tachycardia and pruritis were all reported after a single dose of ivermectin treatment. ${ }^{85}$ However, these adverse effects are related to the patient's immune response (Mazzotti reaction) to dead microfilariae and not toxicity from the ivermectin. The severity of the Mazzotti reaction is directly related to the initial intensity of infection. Thus, the doses of ivermectin used to treat Onchocerciasis are much lower than the anticipated anti-tumor concentrations and may partly explain why anti-cancer effects of ivermectin have not been previously observed. However, doses of ivermectin much higher than those required to treat Onchocerciasis have been administered to humans as part of the evaluation of this agent for other indications such as muscle spasticity and are within the range of doses we anticipate are required for an anti-tumor effect. ${ }^{30}$ Of note, in patients without onchocerciasis, Mazzotti reactions were not observed and ivermectin was well tolerated. For example, in patients with spinal injury and resultant muscle spasticity, up to $1.6 \mathrm{mg} / \mathrm{kg}$ of ivermectin was administered subcutaneously at twice weekly for up to 12 weeks. ${ }^{30}$ Finally, reports of ivermectin overdoses also support the potential wide therapeutic window with this drug. For example, a 43 year old female in the UK with a paranoid delusional disorder self-administered $6 \mathrm{~g}$ of veterinary Ivermectin 30 to 50 times over the course of one year, along with furosemide and steroids. She was admitted to a London hospital for a full evaluation. Except for a Cushingoid appearance and hypokalemia, no other abnormalities were noted. ${ }^{32}$ Multiple other ingestion events have also been reported, particularly in pediatric subjects who accidentally consumed of veterinary ivermectin kept in the household for the family dog. In the majority of these, no serious adverse events were reported. ${ }^{30,32}$ 
Our studies suggest that ivermectin-induced cell death is related to its known function as an activator of chloride channels. As an anti-parasitic, ivermectin activates glutamate-gated chloride channels unique to invertebrates. However, at higher concentrations ivermectin can also activates mammalian chloride channels. ${ }^{28}$ Mammalian chloride channels broadly fall into five classes based on their regulation: cystic fibrosis transmembrane conductance regulator (CFTR), which is activated by cyclic AMP dependent phosphorylation; calcium activated chloride channels (CaCCs); voltage gated chloride channels (ClCs); ligand gated chloride channels (GABA ( $\gamma$ aminobutyric acid) and glycine activated); and volume regulated chloride channels. Members of voltage gated chloride channels contain nine subtypes, $\mathrm{ClC}-1$ to $\mathrm{ClC}-7$, and $\mathrm{ClC}-\mathrm{Ka}$ and $\mathrm{ClC}-\mathrm{Kb}$ and ligand gated chloride channels act in heteromeric complexes dependent upon cell type, with multiple permutations and combinations of the subunits. ${ }^{45}$ Currently, it is unclear which mammalian chloride channels are being activated by ivermectin, but this issue is being actively addressed.

Cells require ion channel function to maintain basic homeostatic parameters, such as intracellular $\mathrm{Ca} 2+, \mathrm{pH}$ and cell volume, and to allow uptake of substrates and release of metabolic products. ${ }^{57}$ Strikingly, both inhibition and activation of chloride channel activity can disrupt cellular homeostasis and impair proliferation and survival. However, the mechanisms and downstream effectors of cell death are not fully understood. Of note, malignant cells appear more sensitive to alterations in intracellular Chloride concentration, compared to untransformed cells. The basis for this therapeutic window is unclear, but may relate to increased expression of Chloride channels on the surface of malignant cells, or to increased sensitivity to Chloride channel agonists and 
antagonists. ${ }^{62,63}$ Malignant cells are also more sensitive to changes in cell volume, which may also explain the observed therapeutic window. ${ }^{53}$

Our in vitro studies with peripheral blood stem cells, patient samples and leukemia cell line demonstrated a wide therapeutic window between the cytotoxicity of ivermectin for primary AML and normal hematopoietic cells. On the contrary, the narrow difference observed between patient samples and normal hematopoietic cells in clonogenic assays raises concerns regarding the potential therapeutic window of ivermectin. However, it is important to note that results of colony formation assays do not always predict clinical toxicity. For example, cytarabine and m-AMSA are chemotherapeutic agents routinely used in the treatment of AML, but show little or no selectivity for malignant cells over normal cells in colony formation assays. ${ }^{86,87}$ In addition, we demonstrated that oral ivermectin delayed tumor growth in three mouse models of leukemia without untoward toxicity, supporting a therapeutic window. Finally, toxicology studies with ivermectin in animals and humans did not report hematologic toxicity. Nonetheless, the small differential sensitivity between primary AML and normal hematopoietic cells raises concerns about the potential hematologic toxicity and its safety will have to be carefully evaluated in phase I clinical trials.

A functional chloride channel and chloride conductance is required for betaamyloid protein to induce generation of neurotoxic ROS in microglia cells. ${ }^{88}$ Furthermore, addition of cobalt chloride, manganese chloride and mercuric chloride to brain cells increase ROS production as well. ${ }^{78,89,90}$ Therefore, we examined the effects of ivermectin on ROS production in leukemia cells and demonstrated that cytotoxic concentrations of ivermectin increased levels of ROS. ROS generation appeared 
functionally important for ivermectin-induced death as pre-treatment with the antioxidant $\mathrm{N}$-acetyl-L-cysteine (NAC) inhibited ivermectin-induced cell death. Ivermectin-mediated ROS production may also explain why malignant cells are more sensitive to ivermectin compared to normal cells as malignant cells have higher basal levels of ROS and are less tolerant ROS-inducing agents compared to normal cells..$^{91,92}$

Cyatarabine and daunorubicin, which are used in the treatment of AML induce induce ROS generation, but through a mechanism linked to DNA damage and thus a mechanism distinct from ivermectin. Therefore, we evaluated the combination of these drugs with ivermectin and demonstrated synergy with both of these drugs. Therefore, ivermectin might be used in combination with these agents to enhance the efficacy of standard therapy for AML.

In summary, we have shown that ivermectin can be used for this new indication as a novel anti-cancer drug as it induces a cytotoxic effect in malignant cells via chloride influx, membrane hyperpolarization and increasing levels of intracellular reactive oxygen species. Given its prior safety record in humans and animals coupled with its pre-clinical efficacy in hematological malignancies, a phase 1 clinical trial has been designed to evaluate the tolerance and biological activity of oral ivermectin in patients with relapsed or refractory hematological malignancies. 


\section{Future Directions}

To further our goal of recycling the FDA approved anit-parasitic agent, ivermectin, as a novel chemotherapeutic agent using the knowledge from our in vitro and in vivo studies, we can carry out a clinical trial to investigate its potency in treating patients with relapsed hematological malignancies. Furthermore, to elucidate more on the mechanism, we can perform a global gene expression array analysis and a functional lentiviral screen to identify genes that confer ivermectin resistance. These various approaches that can be explored in the future are described below to investigate the potency of ivermectin in patients and understand its mechanism of action in greater details.

\section{Clinical Trial}

Given the known toxicity and pharmacological data available on ivermectin along with our pre-clinical data to show its anti-leukemia potential, we proposed a Phase I clinical trial to the Research Ethics Board of Princess Margaret Hospital and Health Canada. The primary objectives of the clinical trial are two fold: first, to evaluate the dose-limiting toxicity, maximum tolerated dose and recommended phase II dose of ivermectin in patients with relapsed or refractory hematological malignancies and secondly to partially characterize the pharmacokinetics of ivermectin in plasma following single and multiple oral dosing for 7 days at increasing dose levels in patients with relapsed or refractory hematological malignancy. In addition, the observed steady-state 
concentrations, dose linearity and changes in the pharmacokinetic parameters between single versus multiple dosing can also be reported.

The secondary objectives of this clinical trial are to examine the role of chloride channels by observing the pharmacodynamic effects of ivermectin on these channels and relate to the steady-state plasma concentrations of ivermectin following multiple oral dosing of ivermectin after seven days. We would also like to determine the response rate of ivermectin in patients with relapsed or refractory hematological malignancies.

The clinical trial with ivermectin will be a prospective, single arm, open label study and phase I dose escalation will occur with ivermectin. The starting dose will be $100 \mu \mathrm{g} / \mathrm{kg} /$ day as a single dose daily for seven days and seven dose levels will be studied to reach the final escalated dose to be $2600 \mu \mathrm{g} / \mathrm{kg} / \mathrm{day}$ for seven days. Since ivermectin is a hydrophobic compound, its bioavailability is increased 2.5 fold following a high fat meal. Thus, ivermectin will be administered daily orally with food for a total of 7 doses ( 1 cycle) and response to ivermectin will be determined on day 21. Dose escalation decisions will be made after the assigned patients within a dose level have all completed 1 cycle and adverse events occurring after the first cycle of administration of ivermectin will also be considered in dose escalating decisions.

\section{Gene expression array analysis}

DNA array technology offers an alternative tool that allows studying thousands of genes simultaneously. We can take advantage of such human genome chip arrays to identify genes that are differentially expressed, i.e. upregulated or downregulated, due to 
ivermectin treatment. Consequently, gene expression array analysis may help to provide key information about genes that are targeted directly or indirectly by ivermectin.

In this experiment, cells can be cultured and treated with ivermectin at varying concentrations and time points along with untreated cells (controls). Treating cells at various time points would permit the observation of genes that are affected immediately versus over a long duration. Moreover, treating at different concentrations of ivermectin such as LD25, LD50, LD90 would allow us to examine the genes that are directly affected. Presumably at high concentration (i.e. LD90), we would see many more genes differentially expressed when compared to the treatment at LD25. Thus, when analyzing the data, we would need to find the subset of genes that are common to both of these treatments.

It is possible that we will identify many genes that are either upregulated or downregulated due to ivermectin treatment. Thus, we will need to find an appropriate measure of cut-off (i.e. two fold or four fold) to identify genes that are differentially expressed. Alternatively, we can apply statistical methods to identify genes that are significantly overexpressed or underexpressed when compared to control (untreated) cells. Once those genes are identified, we can take several routes. We can use bioinformatics tools and curated literature search to identify pathways that are being affected by those genes. We can look at specific chloride channels or other ligand gated channels to investigate if their expression levels change due to ivermectin treatment. Since we know that ivermectin induces ROS generation, we can also look for genes that are involved in the ROS pathways such as STAT1 and evaluate their expression patterns after ivermectin treatment. Once hits are identified from the array data, we would then 
need to validate them by following up on certain genes that are of interest by RT-PCR or Western blot to ensure that the changes observed in mRNA levels translates to protein level as well.

Gene expression array analysis can help us observe the global expression pattern changes due to ivermectin treatment and identify genes that are being affected. This is particularly relevant to clinical settings because by finding genes that are upregulated or downregulated upon ivermectin treatment, we can identify novel biomarkers that can be useful for the clinical trial.

\section{Lentiviral shRNA screen to identify genes in the Ivermectin response pathway}

Although it is evident that ivermectin acts by increasing the intracellular Chloride concentration, it is not clear as to which channel it targets or the genes involved in the mechanism that leads to ivermectin sensitivity. Thus, to elucidate and identify genes responsible for ivermectin response, a genome-scale screening study may be helpful. The discovery of RNA interference (RNAi) in model organisms such as c. elegans and $D$. melanogaster has led to the identification and understanding of many complex biological

processes. ${ }^{93} 94$ In mammals, chemically synthesized RNAs (siRNAs) can function in a similar manner as RNAi to suppress gene expression and thus have become important tools for biological studies. However, due to resistance of many mammalian cells to transfection methods needed to introduce siRNAs into cells, for the purpose of this study, I would like to use an alternative approach using short hairpin RNAs (shRNAs).

We can achieve highly effective and stable gene suppression in a variety of mammalian cells by transducing mammalian cells with viruses carrying expression 
cassettes that encode shRNAs to generate gene specific siRNAs. The virus is integrated into the genome, thus it is a stable knock down of the target gene. We can perform an arrayed screen, in which each shRNA is tested in an individual well and high-content automated imaging of cells in individual wells can be performed to identify genes that confer resistance to ivermectin when suppressed. Using the RNAi Consortium (TRC) lentiviral library, researchers have identified genes required for mitotic progression in human cancer cells. ${ }^{95}$ The TRC library contains constructs targeting 22,000 human and mouse genes, with $\sim 5$ distinct shRNA constructs per gene that allows the functional validation of putative hits. Thus, I can use the TRC library in an arrayed screen to identify genes that lead to ivermectin resistance when knocked down and may be essential in ivermectin response mechanism.

In order to carry out such an arrayed screen, I would first need to know if the cell lines sensitive to ivermectin can actually be infected by the virus and to do this, we can use virus that contain hairpins that target non-essential genes (GFP, RFP, Luciferase). The next step would be to optimize infection conditions, such as transduction in 96 well plates for optimal growth conditions, viral dosage, puromycin selection concentration and assay times prior to screening. Cells can be seeded in two sets of plates, i.e. A and B, on the first day and then optimal amount of lentiviral particles encoding shRNA against different genes can be added to appropriate wells to incubate for three days to allow for selection of cells that have been successfully transduced. Once transduction takes place, plate A can be kept as the control without addition of ivermectin and a sublethal dose of ivermectin can be added for plates in set B. After incubating in these conditions for 
several days, the number of viable cells can be determined using an automated cell cytotoxicity assay.

In this experimental design, the control plates (set A) would be used to evaluate transduction efficiency and to exclude target genes that are lethal during knockdown in the absence of chemotherapy. The plates in set B will be given both lentiviral shRNA, puromycin and a dose of ivermectin that is sublethal for the cell line and a positive result would be cells that survive ivermectin treatment due to knockdown of an essential gene responsible for ivermectin response. shRNA targeted genes that are associated with cells surviving in plate A and B will be identified as "hits" and selected for further study. Since each of the genes is represented by three to five different shRNA lentiviral particle constructs targeting different sites in each gene, only those genes that are identified as functional drug resistance genes by two or more shRNA targeting the same gene would be called putative "hits". A pitfall in such screens is that the viral vector integration can cause disruption of essential genes and lead to false hits. Thus, once hits are identified, we would need to carry out secondary screens in a similar manner with shRNAs that showed resistance to ivermectin when transduced into cells. Lastly, we will validate that the targeted genes indeed have been knocked down by RT-PCR and Western blot analysis. 


\section{Conclusion}

In summary, we have shown that ivermectin can be repurposed as a novel anticancer drug as it induces a cytotoxic effect in malignant cells via chloride influx,

membrane hyperpolarization and increasing levels of intracellular reactive oxygen species. Given its prior safety record in humans and animals coupled with its pre-clinical efficacy in hematological malignancies, we are hopeful that the phase 1 clinical trial designed to evaluate the tolerance and biological activity of oral ivermectin in patients with relapsed or refractory hematological malignancies will lead to identifying ivermectin as an anti-cancer agent. Furthermore, targeting chloride channels for the treatment of AML is a novel approach. Thus, findings from this study and future work with the antiparasitic agent can shed light on the many unanswered questions of biological roles chloride channels play in clinical manifestation of malignancies. Ivermectin may provide a less toxic and less expensive alternative treatment option for patients with AML. 


\section{References}

1. Dong F, van Paassen M, van Buitenen C, Hoefsloot LH, Lowenberg B, Touw IP. A point mutation in the granulocyte colony-stimulating factor receptor (G-CSF-R) gene in a case of acute myeloid leukemia results in the overexpression of a novel G-CSF-R isoform. Blood. 1995;85:902-911.

2. Preudhomme C, Warot-Loze D, Roumier C, et al. High incidence of biallelic point mutations in the Runt domain of the AML1/PEBP2 alpha B gene in Mo acute myeloid leukemia and in myeloid malignancies with acquired trisomy 21 . Blood. 2000;96:2862-2869.

3. Brissette MD, Duval-Arnould BJ, Gordon BG, Cotelingam JD. Acute megakaryoblastic leukemia following transient myeloproliferative disorder in a patient without Down syndrome. Am J Hematol. 1994;47:316-319.

4. Lerner HJ. Acute myelogenous leukemia in patients receiving chlorambucil as long-term adjuvant chemotherapy for stage II breast cancer. Cancer Treat Rep. 1978;62:1135-1138.

5. Pedersen-Bjergaard J, Philip P, Larsen SO, et al. Therapy-related myelodysplasia and acute myeloid leukemia. Cytogenetic characteristics of 115 consecutive cases and risk in seven cohorts of patients treated intensively for malignant diseases in the Copenhagen series. Leukemia. 1993;7:1975-1986.

6. Larson RA, Le Beau MM, Vardiman JW, Testa JR, Golomb HM, Rowley JD. The predictive value of initial cytogenetic studies in 148 adults with acute nonlymphocytic leukemia: a 12-year study (1970-1982). Cancer Genet Cytogenet. 1983;10:219-236.

7. Marosi C, Koller U, Koller-Weber E, et al. Prognostic impact of karyotype and immunologic phenotype in 125 adult patients with de novo AML. Cancer Genet Cytogenet. 1992;61:14-25.

8. Fonatsch C, Gudat H, Lengfelder E, et al. Correlation of cytogenetic findings with clinical features in 18 patients with inv(3)(q21q26) or $\mathrm{t}(3 ; 3)(\mathrm{q} 21 ; \mathrm{q} 26)$. Leukemia. 1994;8:1318-1326.

9. Grimwade D, Walker H, Oliver F, et al. The importance of diagnostic cytogenetics on outcome in AML: analysis of 1,612 patients entered into the MRC AML 10 trial. The Medical Research Council Adult and Children's Leukaemia Working Parties. Blood. 1998;92:2322-2333.

10. Abu-Duhier FM, Goodeve AC, Wilson GA, et al. FLT3 internal tandem duplication mutations in adult acute myeloid leukaemia define a high-risk group. $\mathrm{Br} \mathbf{J}$ Haematol. 2000;111:190-195.

11. Snaddon J, Smith ML, Neat M, et al. Mutations of CEBPA in acute myeloid leukemia FAB types M1 and M2. Genes Chromosomes Cancer. 2003;37:72-78.

12. Farag SS, Archer KJ, Mrozek K, et al. Pretreatment cytogenetics add to other prognostic factors predicting complete remission and long-term outcome in patients 60 years of age or older with acute myeloid leukemia: results from Cancer and Leukemia Group B 8461. Blood. 2006;108:63-73. 
13. Schnittger S, Kinkelin U, Schoch C, et al. Screening for MLL tandem duplication in 387 unselected patients with AML identify a prognostically unfavorable subset of AML. Leukemia. 2000;14:796-804.

14. Santamaria C, Chillon MC, Garcia-Sanz R, et al. BAALC is an important predictor of refractoriness to chemotherapy and poor survival in intermediate-risk acute myeloid leukemia (AML). Ann Hematol. 2009.

15. Dohner K, Schlenk RF, Habdank M, et al. Mutant nucleophosmin (NPM1) predicts favorable prognosis in younger adults with acute myeloid leukemia and normal cytogenetics: interaction with other gene mutations. Blood. 2005;106:3740-3746.

16. Dillman RO, Davis RB, Green MR, et al. A comparative study of two different doses of cytarabine for acute myeloid leukemia: a phase III trial of Cancer and Leukemia Group B. Blood. 1991;78:2520-2526.

17. Weick JK, Kopecky KJ, Appelbaum FR, et al. A randomized investigation of high-dose versus standard-dose cytosine arabinoside with daunorubicin in patients with previously untreated acute myeloid leukemia: a Southwest Oncology Group study. Blood. 1996;88:2841-2851.

18. Lowenberg B, Suciu S, Archimbaud E, et al. Mitoxantrone versus daunorubicin in induction-consolidation chemotherapy--the value of low-dose cytarabine for maintenance of remission, and an assessment of prognostic factors in acute myeloid leukemia in the elderly: final report. European Organization for the Research and Treatment of Cancer and the Dutch-Belgian Hemato-Oncology Cooperative Hovon Group. J Clin Oncol. 1998;16:872-881.

19. Kell J. Treatment of relapsed acute myeloid leukaemia. Rev Recent Clin Trials. 2006;1:103-111.

20. Archimbaud E, Leblond V, Michallet M, et al. Intensive sequential chemotherapy with mitoxantrone and continuous infusion etoposide and cytarabine for previously treated acute myelogenous leukemia. Blood. 1991;77:1894-1900.

21. Keating MJ, Kantarjian H, Smith TL, et al. Response to salvage therapy and survival after relapse in acute myelogenous leukemia. J Clin Oncol. 1989;7:1071-1080.

22. Tan K, Culjkovic B, Amri A, Borden KL. Ribavirin targets eIF4E dependent Akt survival signaling. Biochem Biophys Res Commun. 2008;375:341-345.

23. Kentsis A, Topisirovic I, Culjkovic B, Shao L, Borden KL. Ribavirin suppresses eIF4E-mediated oncogenic transformation by physical mimicry of the 7-methyl guanosine mRNA cap. Proc Natl Acad Sci U S A. 2004;101:18105-18110.

24. Assouline S, Culjkovic B, Cocolakis E, et al. Molecular targeting of the oncogene eIF4E in acute myeloid leukemia (AML): a proof-of-principle clinical trial with ribavirin. Blood. 2009;114:257-260.

25. Sella A, Kilbourn R, Amato R, et al. Phase II study of ketoconazole combined with weekly doxorubicin in patients with androgen-independent prostate cancer. J Clin Oncol. 1994;12:683-688.

26. Small EJ, Halabi S, Dawson NA, et al. Antiandrogen withdrawal alone or in combination with ketoconazole in androgen-independent prostate cancer patients: a phase III trial (CALGB 9583). J Clin Oncol. 2004;22:1025-1033.

27. Mao X, Li X, Sprangers R, et al. Clioquinol inhibits the proteasome and displays preclinical activity in leukemia and myeloma. Leukemia. 2009;23:585-590. 
28. Dadarkar SS, Deore MD, Gatne MM. Comparative evaluation of acute toxicity of ivermectin by two methods after single subcutaneous administration in rats. Regul Toxicol Pharmacol. 2007;47:257-260.

29. Brown KR, Ricci FM, Ottesen EA. Ivermectin: effectiveness in lymphatic filariasis. Parasitology. 2000;121 Suppl:S133-146.

30. Costa JL, Diazgranados JA. Ivermectin for spasticity in spinal-cord injury. Lancet. 1994;343:739.

31. Guzzo CA, Furtek CI, Porras AG, et al. Safety, tolerability, and pharmacokinetics of escalating high doses of ivermectin in healthy adult subjects. J Clin Pharmacol. 2002;42:1122-1133.

32. Frost M. FDA New Drug Application (NDA) for STROMECTOL (ivermectin) 6$\mathrm{mg}$ for the treatment of strongyloidiasis and onchocerciasis.; 1996.

33. Wang CC, Pong SS. Actions of avermectin B1a on GABA nerves. Prog Clin Biol Res. 1982;97:373-395.

34. Terada M, Ishii AI, Kino H, Sano M. Angiostrongylus cantonensis: paralysis due to avermectin B1a and ivermectin. Exp Parasitol. 1984;57:149-157.

35. Holden-Dye L, Walker RJ. Avermectin and avermectin derivatives are antagonists at the 4-aminobutyric acid (GABA) receptor on the somatic muscle cells of Ascaris; is this the site of anthelmintic action? Parasitology. 1990;101 Pt 2:265-271.

36. Kass IS, Stretton AO, Wang CC. The effects of avermectin and drugs related to acetylcholine and 4-aminobutyric acid on neurotransmission in Ascaris suum. Mol Biochem Parasitol. 1984;13:213-225.

37. Schaeffer JM, Haines HW. Avermectin binding in Caenorhabditis elegans. A twostate model for the avermectin binding site. Biochem Pharmacol. 1989;38:2329-2338.

38. Arena JP, Liu KK, Paress PS, Schaeffer JM, Cully DF. Expression of a glutamateactivated chloride current in Xenopus oocytes injected with Caenorhabditis elegans RNA: evidence for modulation by avermectin. Brain Res Mol Brain Res. 1992;15:339-348.

39. Arena JP, Liu KK, Paress PS, et al. The mechanism of action of avermectins in Caenorhabditis elegans: correlation between activation of glutamate-sensitive chloride current, membrane binding, and biological activity. J Parasitol. 1995;81:286-294.

40. Cully DF, Vassilatis DK, Liu KK, et al. Cloning of an avermectin-sensitive glutamate-gated chloride channel from Caenorhabditis elegans. Nature. 1994;371:707711.

41. Pemberton DJ, Franks CJ, Walker RJ, Holden-Dye L. Characterization of glutamate-gated chloride channels in the pharynx of wild-type and mutant Caenorhabditis elegans delineates the role of the subunit GluCl-alpha2 in the function of the native receptor. Mol Pharmacol. 2001;59:1037-1043.

42. Tandon R, LePage KT, Kaplan RM. Cloning and characterization of genes encoding alpha and beta subunits of glutamate-gated chloride channel protein in Cylicocyclus nassatus. Mol Biochem Parasitol. 2006;150:46-55.

43. Njue AI, Prichard RK. Genetic variability of glutamate-gated chloride channel genes in ivermectin-susceptible and -resistant strains of Cooperia oncophora. Parasitology. 2004;129:741-751.

44. Liu J, Dent JA, Beech RN, Prichard RK. Genomic organization of an avermectin receptor subunit from Haemonchus contortus and expression of its putative promoter region in Caenorhabditis elegans. Mol Biochem Parasitol. 2004;134:267-274. 
45. Verkman AS, Galietta LJ. Chloride channels as drug targets. Nat Rev Drug Discov. 2009;8:153-171.

46. Demaurex N, Furuya W, D'Souza S, Bonifacino JS, Grinstein S. Mechanism of acidification of the trans-Golgi network (TGN). In situ measurements of $\mathrm{pH}$ using retrieval of TGN38 and furin from the cell surface. J Biol Chem. 1998;273:2044-2051.

47. Jentsch TJ, Stein V, Weinreich F, Zdebik AA. Molecular structure and physiological function of chloride channels. Physiol Rev. 2002;82:503-568.

48. Amaral MD, Kunzelmann K. Molecular targeting of CFTR as a therapeutic approach to cystic fibrosis. Trends Pharmacol Sci. 2007;28:334-341.

49. Klocke R, Steinmeyer K, Jentsch TJ, Jockusch H. Role of innervation, excitability, and myogenic factors in the expression of the muscular chloride channel ClC-1. A study on normal and myotonic muscle. J Biol Chem. 1994;269:27635-27639.

50. Yin LT, Fu YJ, Xu QL, et al. Potential biochemical therapy of glioma cancer. Biochem Biophys Res Commun. 2007;362:225-229.

51. Arcangeli A, Crociani O, Lastraioli E, Masi A, Pillozzi S, Becchetti A. Targeting ion channels in cancer: a novel frontier in antineoplastic therapy. Curr Med Chem. 2009; 16:66-93.

52. Lang F, Lepple-Wienhues A, Paulmichl M, Szabo I, Siemen D, Gulbins E. Ion channels, cell volume, and apoptotic cell death. Cell Physiol Biochem. 1998;8:285-292.

53. Jiang B, Hattori N, Liu B, et al. Expression and roles of Cl- channel ClC-5 in cell cycles of myeloid cells. Biochem Biophys Res Commun. 2004;317:192-197.

54. Nilius B. Chloride channels go cell cycling. J Physiol. 2001;532:581.

55. Zheng YJ, Furukawa T, Tajimi K, Inagaki N. Cl- channel blockers inhibit transition of quiescent (G0) fibroblasts into the cell cycle. J Cell Physiol. 2003;194:376383.

56. Ullrich N, Sontheimer H. Cell cycle-dependent expression of a glioma-specific chloride current: proposed link to cytoskeletal changes. Am J Physiol. 1997;273:C12901297.

57. Kunzelmann K. Ion channels and cancer. J Membr Biol. 2005;205:159-173.

58. Miller GW, Schnellmann RG. Cytoprotection by inhibition of chloride channels: the mechanism of action of glycine and strychnine. Life Sci. 1993;53:1211-1215.

59. Szabo I, Lepple-Wienhues A, Kaba KN, Zoratti M, Gulbins E, Lang F. Tyrosine kinase-dependent activation of a chloride channel in CD95-induced apoptosis in $\mathrm{T}$ lymphocytes. Proc Natl Acad Sci U S A. 1998;95:6169-6174.

60. Maeno E, Ishizaki Y, Kanaseki T, Hazama A, Okada Y. Normotonic cell shrinkage because of disordered volume regulation is an early prerequisite to apoptosis. Proc Natl Acad Sci U S A. 2000;97:9487-9492.

61. Lang F, Foller M, Lang K, et al. Cell volume regulatory ion channels in cell proliferation and cell death. Methods Enzymol. 2007;428:209-225.

62. Wang JW, Peng SY, Li JT, et al. Identification of metastasis-associated proteins involved in gallbladder carcinoma metastasis by proteomic analysis and functional exploration of chloride intracellular channel 1. Cancer Lett. 2009;281:71-81.

63. Abdel-Ghany M, Cheng HC, Elble RC, Pauli BU. The breast cancer beta 4 integrin and endothelial human CLCA2 mediate lung metastasis. J Biol Chem. 2001;276:25438-25446. 
64. Simpson CD, Mawji IA, Anyiwe K, et al. Inhibition of the sodium potassium adenosine triphosphatase pump sensitizes cancer cells to anoikis and prevents distant tumor formation. Cancer Res. 2009;69:2739-2747.

65. Mawji IA, Simpson CD, Hurren R, et al. Critical role for Fas-associated death domain-like interleukin-1-converting enzyme-like inhibitory protein in anoikis resistance and distant tumor formation. J Natl Cancer Inst. 2007;99:811-822.

66. Buick RN, Till JE, McCulloch EA. Colony assay for proliferative blast cells circulating in myeloblastic leukaemia. Lancet. 1977;1:862-863.

67. Pilas B, Durack G. A flow cytometric method for measurement of intracellular chloride concentration in lymphocytes using the halide-specific probe 6-methoxy-N-(3sulfopropyl) quinolinium (SPQ). Cytometry. 1997;28:316-322.

68. Gurfinkel DM, Chow S, Hurren R, et al. Disruption of the endoplasmic reticulum and increases in cytoplasmic calcium are early events in cell death induced by the natural triterpenoid Asiatic acid. Apoptosis. 2006;11:1463-1471.

69. Huang ZM, Prasad C, Britton FC, Ye LL, Hatton WJ, Duan D. Functional role of CLC-2 chloride inward rectifier channels in cardiac sinoatrial nodal pacemaker cells. J Mol Cell Cardiol. 2009;47:121-132.

70. Rothbard JB, Jessop TC, Lewis RS, Murray BA, Wender PA. Role of membrane potential and hydrogen bonding in the mechanism of translocation of guanidinium-rich peptides into cells. J Am Chem Soc. 2004;126:9506-9507.

71. Pham NA, Jacobberger JW, Schimmer AD, Cao P, Gronda M, Hedley DW. The dietary isothiocyanate sulforaphane targets pathways of apoptosis, cell cycle arrest, and oxidative stress in human pancreatic cancer cells and inhibits tumor growth in severe combined immunodeficient mice. Mol Cancer Ther. 2004;3:1239-1248.

72. Chou TC, Talalay P. Quantitative analysis of dose-effect relationships: the combined effects of multiple drugs or enzyme inhibitors. Adv Enzyme Regul. 1984;22:27-55.

73. Gonzalez Canga A, Sahagun Prieto AM, Diez Liebana MJ, Fernandez Martinez N, Sierra Vega M, Garcia Vieitez JJ. The pharmacokinetics and interactions of ivermectin in humans--a mini-review. AAPS J. 2008;10:42-46.

74. McCarty MF, Barroso-Aranda J, Contreras F. The hyperpolarizing impact of glycine on endothelial cells may be anti-atherogenic. Med Hypotheses. 2009;73:263-264.

75. Meral I, Hsu W, Hembrough FB. Digoxin- and monensin-induced changes of intracellular $\mathrm{Ca} 2+$ concentration in isolated guinea-pig ventricular myocyte. J Vet Med A Physiol Pathol Clin Med. 2002;49:329-333.

76. Wagner J, Bremhorst T, Schumann HJ. Influence of frequency of stimulation on the toxicity of digoxin on isolated guinea-pig atria in different extracellular $\mathrm{Ca} 2+$. Arch Int Pharmacodyn Ther. 1978;236:228-233.

77. Park EJ, Park K. Induction of reactive oxygen species and apoptosis in BEAS-2B cells by mercuric chloride. Toxicol In Vitro. 2007;21:789-794.

78. Zhang P, Hatter A, Liu B. Manganese chloride stimulates rat microglia to release hydrogen peroxide. Toxicol Lett. 2007;173:88-100.

79. Kamiya T, Hara H, Yamada H, Imai H, Inagaki N, Adachi T. Cobalt chloride decreases EC-SOD expression through intracellular ROS generation and p38-MAPK pathways in COS7 cells. Free Radic Res. 2008;42:949-956. 
80. Tsang WP, Chau SP, Kong SK, Fung KP, Kwok TT. Reactive oxygen species mediate doxorubicin induced p53-independent apoptosis. Life Sci. 2003;73:2047-2058.

81. Iacobini M, Menichelli A, Palumbo G, Multari G, Werner B, Del Principe D. Involvement of oxygen radicals in cytarabine-induced apoptosis in human polymorphonuclear cells. Biochem Pharmacol. 2001;61:1033-1040.

82. Asio SM, Simonsen PE, Onapa AW. Mansonella perstans: safety and efficacy of ivermectin alone, albendazole alone and the two drugs in combination. Ann Trop Med Parasitol. 2009; 103:31-37.

83. Demeler J, Van Zeveren AM, Kleinschmidt N, et al. Monitoring the efficacy of ivermectin and albendazole against gastro intestinal nematodes of cattle in Northern Europe. Vet Parasitol. 2009;160:109-115.

84. Baraka OZ, Mahmoud BM, Marschke CK, Geary TG, Homeida MM, Williams JF. Ivermectin distribution in the plasma and tissues of patients infected with Onchocerca volvulus. Eur J Clin Pharmacol. 1996;50:407-410.

85. Albiez EJ, Newland HS, White AT, et al. Chemotherapy of onchocerciasis with high doses of diethylcarbamazine or a single dose of ivermectin: microfilaria levels and side effects. Trop Med Parasitol. 1988;39:19-24.

86. Singer CR, Linch DC. Comparison of the sensitivity of normal and leukaemic myeloid progenitors to in-vitro incubation with cytotoxic drugs: a study of pharmacological purging. Leuk Res. 1987;11:953-959.

87. Spiro TE, Socquet M, Delforge A, Stryckmans P. Chemotherapeutic sensitivity of normal and leukemic hematopoietic progenitor cells to $\mathrm{N}$-[4-(9-acridinylamino)-3methoxyphenyl]-methanesulfonamide, a new anticancer agent. J Natl Cancer Inst. 1981;66:615-618.

88. Milton RH, Abeti R, Averaimo S, et al. CLIC1 function is required for betaamyloid-induced generation of reactive oxygen species by microglia. $\mathrm{J}$ Neurosci. 2008;28:11488-11499.

89. Hussain S, Rodgers DA, Duhart HM, Ali SF. Mercuric chloride-induced reactive oxygen species and its effect on antioxidant enzymes in different regions of rat brain. $\mathrm{J}$ Environ Sci Health B. 1997;32:395-409.

90. Kotake-Nara E, Saida K. Endothelin-2/vasoactive intestinal contractor: regulation of expression via reactive oxygen species induced by $\mathrm{CoCl} 2$, and Biological activities including neurite outgrowth in PC12 cells. ScientificWorldJournal. 2006;6:176-186.

91. Kong Q, Beel JA, Lillehei KO. A threshold concept for cancer therapy. Med Hypotheses. 2000;55:29-35.

92. Sawayama Y, Miyazaki Y, Ando K, et al. Expression of myeloperoxidase enhances the chemosensitivity of leukemia cells through the generation of reactive oxygen species and the nitration of protein. Leukemia. 2008;22:956-964.

93. Kamath RS, Fraser AG, Dong Y, et al. Systematic functional analysis of the Caenorhabditis elegans genome using RNAi. Nature. 2003;421:231-237.

94. Bettencourt-Dias M, Giet R, Sinka R, et al. Genome-wide survey of protein kinases required for cell cycle progression. Nature. 2004;432:980-987.

95. Moffat J, Grueneberg DA, Yang X, et al. A lentiviral RNAi library for human and mouse genes applied to an arrayed viral high-content screen. Cell. 2006;124:1283-1298. 